\title{
Biobased phenol and furan derivatives coupling for the synthesis of functional monomers
}

\author{
Mélanie Decostanzi, ${ }^{a}$ Rémi Auvergne, ${ }^{a}$ Bernard Boutevin, ${ }^{a}$ Sylvain Caillol ${ }^{a *}$ \\ ${ }^{a}$ ICGM, UMR 5253 - CNRS, Université de Montpellier, ENSCM, 240 Avenue Emile Jeanbrau 34296 \\ Montpellier, France
}

*Corresponding author: Sylvain Caillol, Email: sylvain.caillol@enscm.fr

\section{Graphical Abstract}

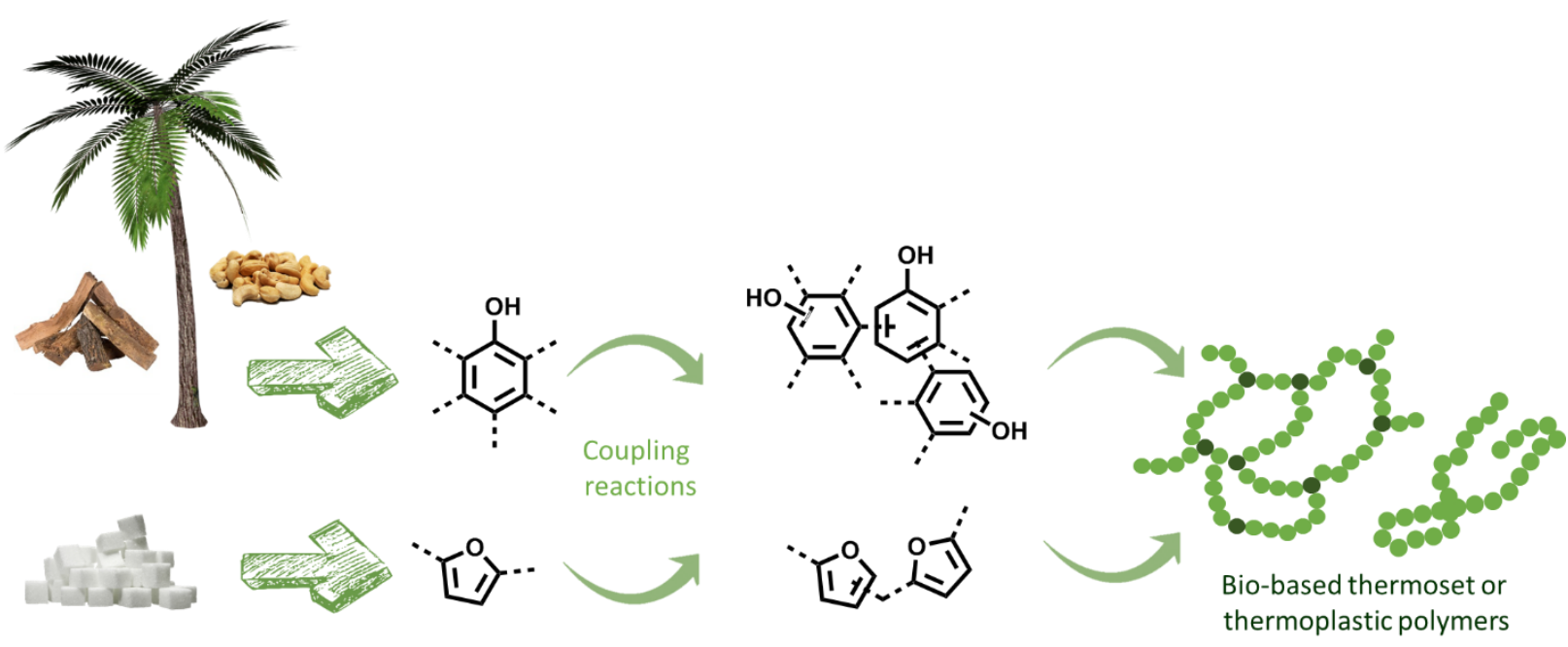

\section{Abstract}

Chemistry in general, but polymer chemistry in particular has to face the major challenge of finding solutions to ensure a sustainable and environmental-benign development of industry to answer consumer needs. Aromatics are very important chemical groups for polymer science for the synthesis of lots of thermostable or thermosetting polymers. However, most petrobased aromatic monomers (such as phenol) are toxic. Finding less toxic and sustainable aromatics is not easy because natural phenols have various functionalities in nature. In consequence aromatic-containing building blocks must be synthesized. The present review gives an overview of the different synthetic methods to prepare such aromatic building blocks by various coupling methods. It then focusses on the synthesis of $\mathrm{C}-\mathrm{C}$ bonds, on reductive coupling of natural aldehydes, on the carbonyl-aromatic coupling and on other various routes to prepare monomers. Indeed, owing to the rich reactivity and properties of aromatics, such functional monomers will undoubtedly lead to the development of high-added value polymers. This review also gives a brief overview of such potential applications.

Keywords: phenol; aldehyde; biobased; aromatic; furan; coupling 


\section{Introduction}

Recently, the replacement of petrosourced or non-renewable resources by bio-based raw materials has become a real challenge. The excessive use of products coming from non-renewable resources depletes the natural global supplies. That is why the development of methods involving molecules originating from biomass has become a major challenge for the chemical, industrial, and academic world. In fact, the interest of renewable chemistry has considerably increased recently. ${ }^{1}$ Many researchers have used biobased polymers that come from sugar (i.e. polyhydroxyalkanoate PHA, chitin) or plants (i.e. triglycerides). ${ }^{2}$

Most of the biobased molecules are extracted from plants, foodstuffs, or synthesized via a bioprocess from microorganisms or enzymes. This natural provenance may be a problem due to the possible fluctuation of the effective composition of the extracted molecules (mixture of molecules). Furthermore, the low abundance of some molecules in natural substances could be a major inconvenience during the industrialization of biobased syntheses. ${ }^{3,4}$ Many biobased molecules are already used such as fatty acids, sugar or starch. However, these resources don't bear aromatic groups. Actually, aromatic substances are major components in the thermoset polymer chemistry giving good thermo-mechanical properties and chemical resistance. Among all the molecules present in nature, phenol derivatives are very abundant. Actually, many natural sources allow the extraction of these phenol derivatives, such as cashew nut shell liquid (CNSL), lignin or palm oil. Lignin or tannin are renewable polymers which have to be depolymerized to give monophenol monomers. Lignin, which is a polymer extracted from wood, allows the extraction of phenol, guaiacol, vanillin, or syringol. ${ }^{5}$ CNSL allows the extraction of molecules derived from cardanol. ${ }^{5}$ Finally, the degradation of palm oil allows to obtain cresol, guaiacol, syringol, or eugenol. ${ }^{5}$ The structures of these compounds are described in Scheme 1. These kind of structures could interestingly replace terephthalate and paraben molecules which are - or are suspected of being - harmful for human health. 


$$
\text { (n) }
$$

Anacardic acid: $\mathrm{R}_{1}=\mathrm{COOH}: \mathrm{R}_{3}=\mathrm{R}_{4}=\mathrm{H}$

Cardanol: $\mathrm{R}_{1}=\mathrm{R}_{3}=\mathrm{R}_{4}=\mathrm{H}$

Cardol: $\mathrm{R}_{1}=\mathrm{R}_{4}=\mathrm{H} ; \mathrm{R}_{3}=\mathrm{OH}$

2-methylcardol: $\mathrm{R}_{1}=\mathrm{H} ; \mathrm{R}_{3}=\mathrm{OH} ; \mathrm{R}_{4}=\mathrm{CH}_{3}$<smiles>COc1ccc(C=O)cc1OC</smiles>

guaiacol

vanillin syringol<smiles>COc1cc(C=O)cc(OC)c1O</smiles>

syringaldehyde

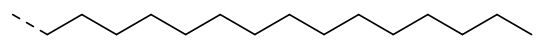

$\mathrm{R}_{2}=$
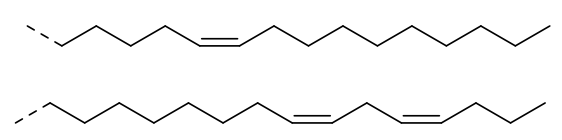

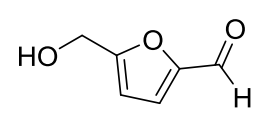

HMF

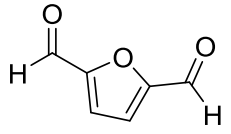

furfural

Scheme 1: Structure of some biobased phenol and furan derivatives.

On another hand, the furanic derivatives, which are pseudo-aromatic molecules, are obtained by the biorefining of $\mathrm{C} 5$ and $\mathrm{C} 6$ carbohydrates (fructose, sucrose, cellulose....). ${ }^{6}$ This process allows furfural and 5-hydroxymethylfurfural (HMF) to be obtained, which can be used for various reactions via their hydroxyl groups and/or their aldehyde function (Scheme 1). ${ }^{6,7}$

However, to synthesize thermoset or thermoplastic polymers, monomers which have a functionality higher than 2 must be used. That is why, the synthesis of polyaromatic or polypseudoaromatic molecules is crucial. Thus, coupling reactions would be beneficial in allowing the access to di- or trifunctional monomers to obtain thermoplastic or thermoset polymers. These transformations are difficult because of the presence of many secondary functions which are non-compatible with the envisaged chemical reactions. Actually, these molecules derived from nature are often highly functional due to the presence of various chemical functions in these tiny molecules (hydroxyl, aldehyde, acid...). Thus, a wide range of coupling methods are available and involve many different types of chemistry through the use of metallic, organometallic, or biochemical catalysts (Figure 1). ${ }^{8,9}$ These molecules could be coupled via their aldehyde function by creating methylene bridges, which can be used as spacers, after which the polymers properties can be modified. Furthermore, multicomponent reactions can also allow to obtain highly selective products from three or more reactants making these syntheses highly convergent and thus improving atom economy. These multicomponent reactions lead to molecules of interest for the field of green chemistry. Indeed, these reactions can be catalyzed, catalyst could be recycled, they could be performed without 
solvents or can be highly atom efficient. In consequence aromatic-containing building blocks could also interestingly be synthesized from these multi-component reactions.

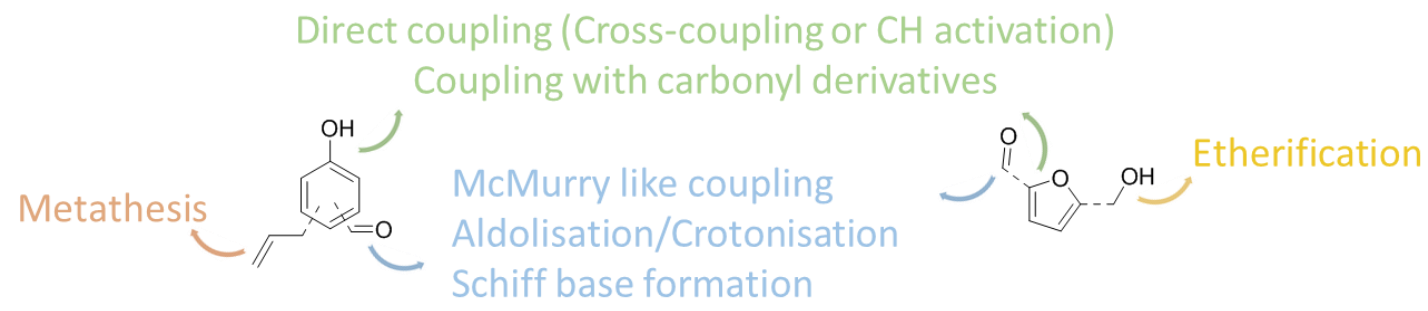

Figure 1: Coupling methods

The polycyclic compounds are particularly interesting because they confer specific properties to polymers such as high transition temperatures, high thermal-resistance, high Young modulus and therefore a high stiffness. These bio-based polycyclic cross-linked or linear polymers could be used in many applications, for health sector, ${ }^{10-12}$ biofuels, ${ }^{13}$ for polyurethanes, ${ }^{14}$ epoxy thermosets, ${ }^{15}$ benzoxazines, ${ }^{16-18}$ functional polymers, ${ }^{19,20}$ composites, ${ }^{21}$ coatings... ${ }^{22}$ A category has been dedicated to furanic compounds as it will be discussed in the following sections.

In this review, we will only focus on aromatic compounds and on furanic compounds and especially on their coupling reactions to form polyfunctional monomers. Due to all the work done in the literature on phenolic and furanic derivatives, it is difficult to be fully exhaustive. This is why this review identifies the chemical reactions that could be performed on phenolic and furanic derivatives through a few examples and discusses their applications. Even though reviews on this topic are present in the literature, ${ }^{5}$ we identified only a few documents which are referencing the coupling reactions of phenolic and furanic derivatives that allow the synthesis of functional monomers for many applications. Moreover, such review papers do not discuss the green aspects of such syntheses. However, some of coupling reactions that allow to obtain promising aromatic building blocks are not really green but should be improved in that direction. Therefore, this review present not only coupling reactions for the synthesis of biobased aromatic building blocks but also discuss the green aspect, potential toxicity and impact of depicted routes. This could help to choose the best coupling reactions in terms of environmental impact or and make decisions about the safest way to obtain various bis- or tri-phenols. This review could also help to determine which routes are the more interesting to improve in order to reduce environmental impacts. Thereby, the aim of the present review is to present both fundamental and applied research pertaining to the coupling of biobased phenols and furan and the preparation of monomers and polymers therefrom. These new monomers and polymers exhibit also novel compositions and architectures that allow to meet cutting-edge properties for promising applications. 


\section{Aromatic-aromatic coupling reactions by formation of $\mathrm{C}-\mathrm{C}$ bond}

The straight coupling of aromatics by the straight formation of an aromatic $\mathrm{C}-\mathrm{C}$ bond allows to obtain convergent building blocks using mild conditions. These coupling reactions, without spacer, were performed by two distinct methods using chemicals or enzymes.

\section{Chemical aromatic-aromatic coupling reactions}

\section{a. Oxidative coupling (C-H activation).}

The oxidative coupling reactions of aromatics uses electron-rich aromatic compounds and metallic catalysts such as copper or iron. Figure 2 shows the products that can be synthesized with these types of reactions.
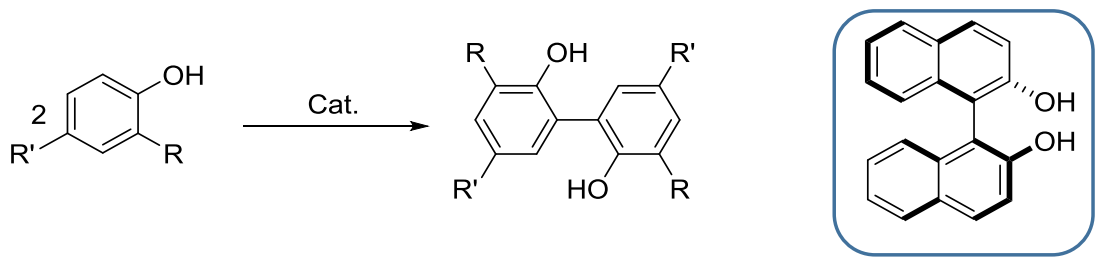

Figure 2: Oxidative coupling reaction between two aromatic moieties and structure of the ( \pm )-BINOL. ${ }^{23}$

One of the most famous example that uses this method is the synthesis of ( \pm )-BINOL (Figure 2). It was synthesized for the first time in 1873 by Von Richter, after which the racemic preparation of this compound via an oxidative coupling was explored many times. ${ }^{23} \mathrm{~A}$ stoichiometric amount of catalyst $\left(\mathrm{FeCl}_{3}\right)$ needs to be used for the synthesis of ( \pm )-BINOL. This catalyst will oxidize the phenol group via a single electron transfer to form an aryloxy radical. The $( \pm)-\mathrm{BINOL}$ is obtained after coupling of the two aryloxy radicals and the loss of a hydrogen radical by oxidation with dioxygen. Since the discovery of this synthesis, many oxidative coupling reactions with bio-based compounds have been developed. Divanillin has been synthesized for the first time in 1885 by Ferd Tiemann using $\mathrm{FeCl}_{3}{ }^{24}$ Many other syntheses, using iron derivatives as catalyst $\left(\mathrm{FeCl}_{3}\right.$ or $\left.\mathrm{FeSO}_{4}\right)$, have been developed. ${ }^{25-29}$ Depending on the experimental conditions, the yields are low (47\%) or almost quantitative (95\%). The ortho position of the phenol was the only isomer obtained. Recently, Harvey et al. have patented the two-step synthesis of a bisphenol from vanillin. The first step consisted of the hydrogenation of the aldehyde function using palladium on carbon as catalyst, followed by the oxidative coupling using a high amount of ammonium permanganate (50 mol\%). ${ }^{30,31}$ A $50 \%$ overall yield was obtained after a purification using column chromatography on silica gel. These monomers were classically transformed into cyanate compounds by reaction of cyanogen bromide on the phenol groups with a yield of $85 \%$ after recrystallization in acetonitrile. 
Most of these reactions use a high amount of catalysts, until stoichiometric amounts. In most of the reported examples, water was used as a solvent which is the greenest solvent that can be used. Interestingly, the group of Nègre-Salvayre ${ }^{28}$ used a catalyst amount of iron sulfate ( 2 mol\%) which respects the green chemistry principles.

\section{b. Cross-coupling $(C-X)$}

Another widespread way to form an aromatic $\mathrm{C}-\mathrm{C}$ bond is the cross-coupling reaction. This reaction needs the use of one or several metallic catalysts and a halogenated aromatic. The first step of the mechanism pathway is the reduction of palladium, which has an oxidation state of +2 to 0 . Then, an oxidative addition of the palladium onto the halogenated aromatic follows. According to the type of cross-coupling reaction, a transmetalation between the palladium moiety and the other metal (boron, tin...) could take place. Finally, a reductive elimination step is performed to give the product of the coupling reaction and to restore the palladium to the 0 oxidation state. The Suzuki reaction ${ }^{32}$ using bio-based molecules was performed by the group of Wadgaonkar. ${ }^{33}$ Cardanol was coupled to an anisole compound, bearing a boronic acid, with an overall yield of $53 \%$ over four steps (Figure 3 ). This synthesis involves protective/deprotective steps of the phenol groups which require purifications on silica gel. These protective steps were done to avoid the reaction of the phenol functions during the coupling reaction but they do not respect the atom efficiency. Furthermore, all reactions are made in hazardous solvents (DMSO, toluene...) which is a crucial parameter to improve.
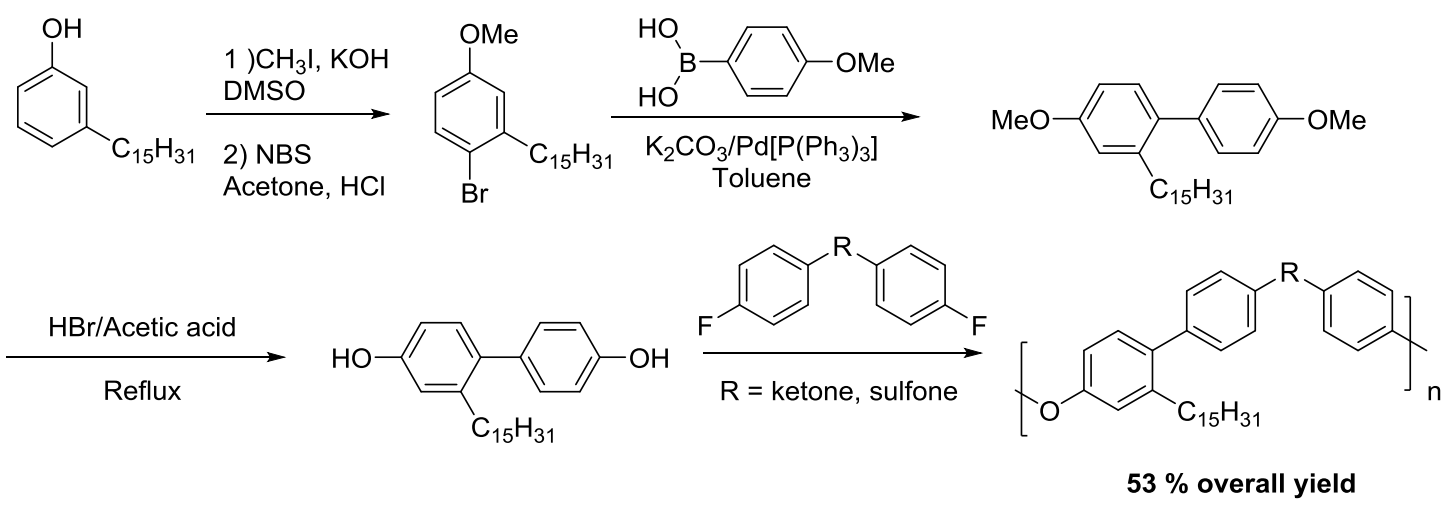

Figure 3: Synthesis of bisphenol from cardanol and anisole and the synthesis of polymers. ${ }^{33}$

This bisphenol was only used in the synthesis of poly(arylene-ethers) by condensation of the bisphenol on fluorinated aromatics. The polymers were characterized by ${ }^{1} \mathrm{H},{ }^{13} \mathrm{C} \mathrm{NMR}$, and by SEC and the properties of the gas permeation of the polymer bearing a sulfonic group were studied and compared to a polysulfone, which doesn't bear an aliphatic chain. It was shown that the gas permeation was higher when cardanol was used due to the aliphatic side chain. The differences were low for lighter gases $\left(\mathrm{He}, \mathrm{H}_{2}\right)$ whereas it was three times higher for heavier gases such as $\mathrm{CO}_{2}$ or $\mathrm{N}_{2}$. These results were explained by the plasticization effect of pentadecyl chains. 
This reaction was also applied to pyrogallol by the group of Schmidt (Figure 4). ${ }^{34}$ This methodology allowed the synthesis of garcibiphenyl or hydroxyaucuparin, which are both phytoalexins (antimicrobial substances synthesized by plants that accumulate rapidly in response to pathogen infection). Microwaves were used in the synthesis with a maximum yield of $70 \%$. Even if chloroform, which is a CMR solvent, is required to form the halogenated product, only a catalytic amount of $\mathrm{NaH}$ was used (1 mol\%). On the other hand, the second step can be regarded as green. Actually, only water is used as a solvent and the process only involves microwaves. Moreover, the use of microwaves is nowadays a method that is easily transferred to industrial scale. Furthermore, the synthesized monomers are non-toxic.<smiles>COc1cccc(OC)c1O</smiles><smiles>COc1cc(Br)cc(OC)c1O</smiles>

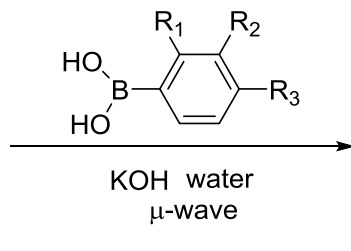

$\mathrm{R}_{1}=\mathrm{R}_{2}=\mathrm{H}: \mathrm{R}_{3}=\mathrm{OH}$ garcibipheny $\mathrm{R}_{1}=\mathrm{R}_{3}=\mathrm{H} ; \mathrm{R}_{2}=\mathrm{OH}$ 3-hydroxyaucuparin $52-72 \%$

Figure 4: Synthesis of garcibiphenyl and hydroxyaucuparin. ${ }^{34}$

Syringaldehyde has also been coupled by the Heck reaction by the group of Sinha (Figure 5). ${ }^{35}$ Totally conjugated triphenols were obtained via a domino sequence Knoevenagel-decarboxylation-Heck. Even if the Heck reaction can be regarded as green, the main drawback of this synthesis is the use of DMF, which is a solvent classified as CMR and should be replaced. These oligo-( $p$ phenylenevinylene)s (OPVs) were synthesized for the first time in a one-pot reaction with a moderate yield (39\%). Furthermore, the authors proved that this kind of structure was capable of selective and visible fluoride recognition, in organic or aqueous medium, for application in organic conducting polymers.<smiles>COc1cc(/C=C/c2cc(/C=C/c3cc(OC)c(O)c(OC)c3)cc(/C=C/c3cc(OC)c(O)c(OC)c3)c2)cc(OC)c1O</smiles>

Figure 5: Knoevenagel-decarboxylation-Heck domino sequence. ${ }^{35}$ 


\section{Enzymatic aromatic-aromatic coupling reactions}

Enzymatic aromatic-aromatic coupling reactions have been used for many years to form bisaromatics using an ecological catalyst. The group of Dordick used this methodology to synthesize divanillin using peroxidase with hydrogen peroxide. They then studied all the products obtained during the reaction of the peroxidase on vanillin. ${ }^{12}$ They have shown that oligomers (dimers, trimers...) and quinolinic derivatives were formed during the reaction and that the main product obtained was a didemethylated tetrameric quinone. They have suggested the following mechanism (Figure 6). However, even though the enzymatic reactions are considered as green reactions, DMF was used to improve the solubility of the substrate and should be replaced. Actually, the major drawback of the use of vanillin is that it is slightly soluble in water $(10 \mathrm{~g} / \mathrm{L})$.

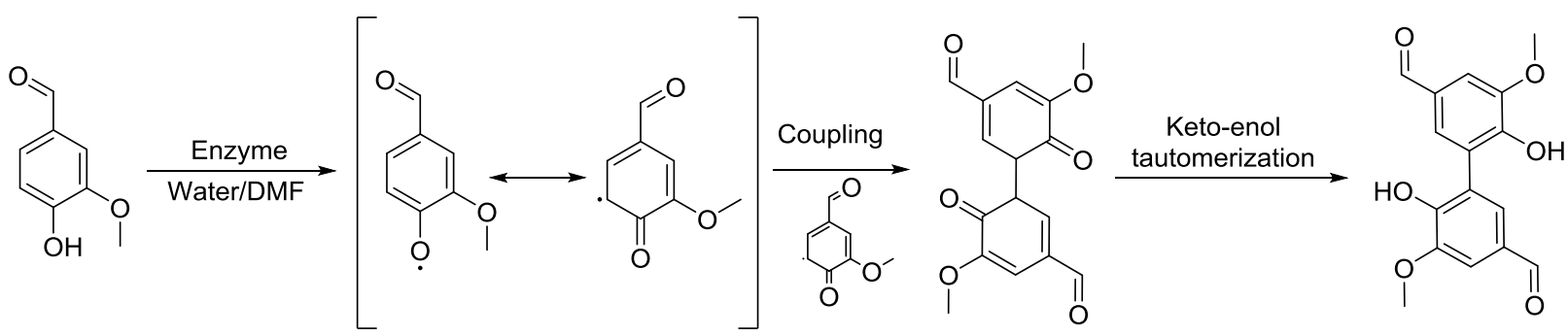

Figure 6: Radical coupling of phenols. ${ }^{12}$

Many patents and publications discuss enzymatic bio-based bisphenol synthesis. ${ }^{36-39}$ The nonexhaustive list of these dimers is presented in Scheme 2.

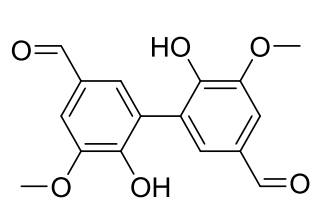

(1)

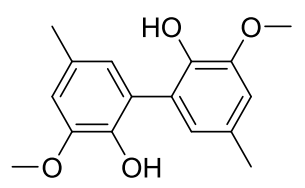

(4)

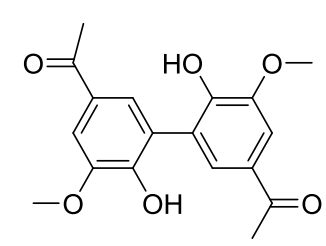

(2)

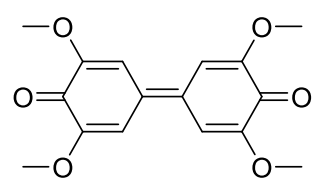

(5)

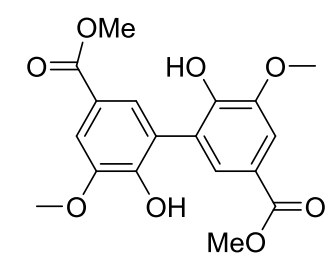

(3)

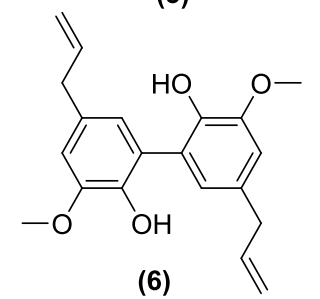<smiles>COc1cc(-c2cc(OC)c(OCC3CO3)c(OC)c2)cc(OC)c1OCC1CO1</smiles>

(7)

Scheme 2: Products obtained during the enzymatic coupling of different phenols. ${ }^{36-39}$ 
The group of Amarasekara has synthesized a polyvanillin from divanillin (Scheme 2-(1)), by electrochemical reaction to form a thermoplastic polymer (Figure 7). ${ }^{36}$ This synthesis only involved bio-based resources and electrolysis and therefore repects the green chemistry principles. An almost quantitative yield of $93 \%$ was obtained over two steps. The authors indicated that these polymers could be used for the chelation of metal ions from aqueous solutions.

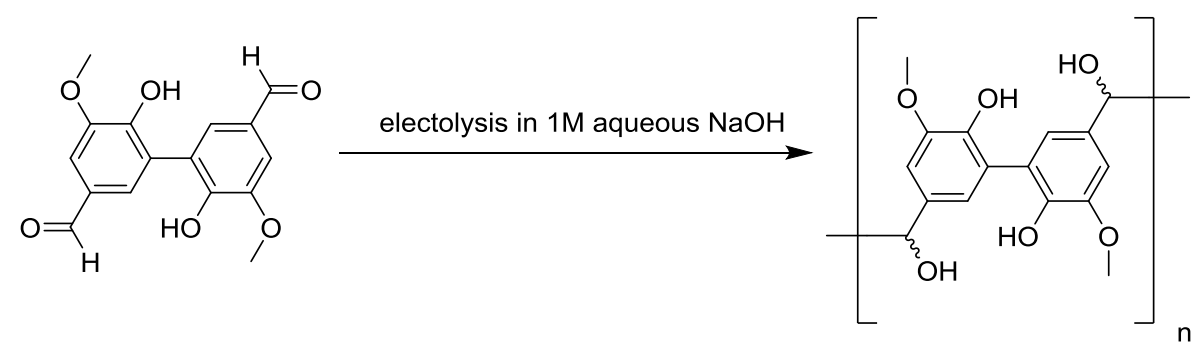

$93 \%$ over 2 steps

Figure 7: Polyvanilline synthesis by electrochemistry. ${ }^{36}$

Cramail et al. studied the coupling of dimethoxy pyrogallol by an enzymatic process using laccase to obtain a quinolinic intermediate (Scheme 2-(5)). ${ }^{38}$ This product was reduced in bisphenols using $\mathrm{NaBH}_{4}$, then transformed in diepoxy by substitution of the chloride of the epichlorohydrin by the hydroxyl moiety (Scheme 2-(7))..$^{40}$ The first step of the synthesis only uses acetone and water as solvents and doesn't use hazardous compounds. However, the use of sodium borohydride should be prohibited because it releases dihydrogen and basic borate salts. Furthermore, epichlorohydrin is a reagent classified as CMR. This synthesis was carried out with a yield of $67 \%$ over three steps. The crosslinking of the diepoxy was performed using isophoronediamine (IPDA) with a molar epoxy/amine ratio of 1 . The thermo-mechanical properties of this thermoset were compared to those of the resin coming from BADGE. ${ }^{41}$ This petroleum-based monomer is one of the most widely used commercial epoxies used in industry. However, the bio-based resin gave lower thermomechanical properties than that from BADGE $\left(T_{g}=126^{\circ} \mathrm{C} v s .152{ }^{\circ} \mathrm{C}\right.$ and $\left.T_{d 5 \%}=312^{\circ} \mathrm{C} v s .349{ }^{\circ} \mathrm{C}\right)$. This can be due to the presence of methoxy groups, which lower the thermal properties of the material. ${ }^{42}$ Among all the industrial applications, the group of Kim prepared biopolyurethane elastomers. ${ }^{29}$ First, a Schiff base is formed by the reaction of ethanolamine onto the aldehyde function of divanillin (Scheme 2-(1)). This diol was used as a chain extender by the addition of different ratios of the latter (from 5 to $20 \%$ ) to an isocyanate prepolymer. They have shown that the higher the diol content, the higher the mechanical properties, due to the presence of more hydroxyl and aromatic functions that helped to stabilize the structure. This method has shown that partially bio-based polyurethanes can be obtained from vanillin. 
Finally, divanillin is important as a flavoring agent and antioxidant in the food, cosmetic and pharmaceutical industry. ${ }^{43}$ It is also used in microlithography and in polymer synthesis as reported previously. ${ }^{44}$ The enzymatic and electrochemical reactions could be considered as green reactions but depending on the monomers, more or less hazardous solvents can be needed.

\section{Aromatic and carbonyl derivatives coupling reactions}

This is the most widely used methodology that led to greater industrial applications. To put this into perspective, bisphenol A (BPA) was synthesized by an aromatic electrophilic substitution and it represents 4 million tons per year in the epoxy and carbonate resins field. ${ }^{45}$ However, it is a substance well known to be an endocrine disruptor. ${ }^{46}$ Actually, bisphenol derivatives interact with the same receptors than natural estrogens. The presence of at least one phenol moiety and a hydrophobic skeleton is an essential characteristic for the estrogenic activity. Studies show that the substitution of the methyl groups of the BPA could decrease its activity. Therefore the careful synthesis of bisphenols is of high interest to avoid the harmfulness of the obtained products.

The principle of the reaction is shown in the Figure 8. First, the phenol adds onto the carbonyl via a Friedel-Craft reaction using an acid catalyst. A substitution step followed by water release leads to the bisphenol moiety. In the case of the synthesis of BPA, the carbonyl used is acetone.

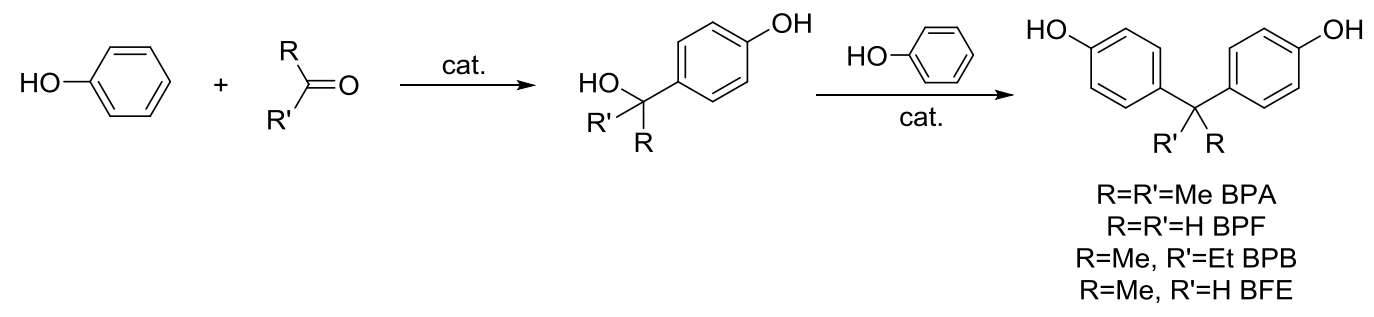

Figure 8: Phenol and carbonyl compounds coupling principle.

When a donating group by mesomeric effect is on the aromatic (such as phenol), ortho and para positions are favored for the aromatic electrophilic substitution. Actually, these positions are stabilized by conjugation of $\pi$ electrons and led to a complex mixture of isomers. However, the para position is widely favored depending on the electrophile involves in the reaction. Actually, the ortho positions could present a high steric hindrance. ${ }^{47}$

There are plenty of patents and publications that discuss these kinds of reactions. That is why only a few examples will be present in the following section. Classical and bio-based carbonyl derivatives (ketone and aldehyde) are given in Table 1.

Table 1: Classical and bio-based carbonyl derivatives. ${ }^{48-53}$ 


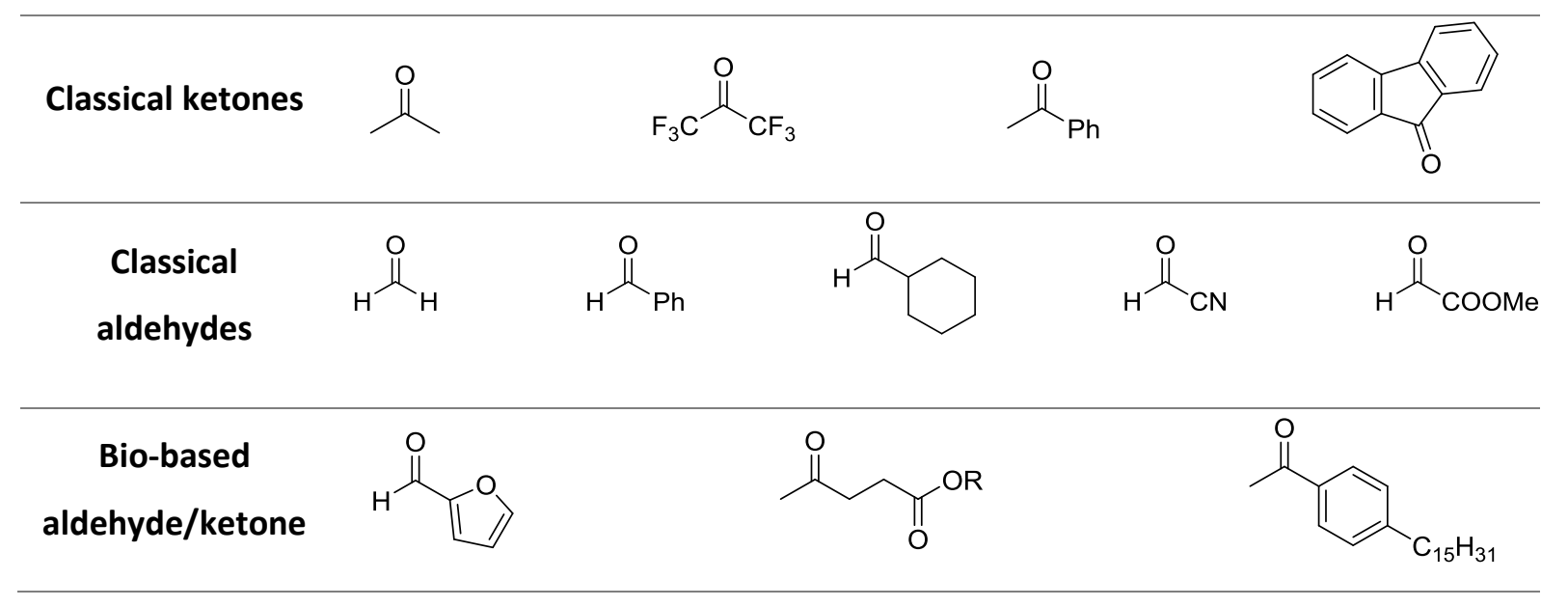

In the following section, only reactions using biobased derivatives will be discussed.

\section{Phenolic derivatives with aldehydes coupling reactions}

Much work has been done with formaldehyde. Actually, this electrophile allows the easy formation of a methylene bridge between two aromatics. Xylenol, another phenol coming from lignin, has been coupled to formaldehyde by acidic catalysis (Scheme $3-(B))$ to produce phenols. ${ }^{54}$ The major drawback of this synthesis is the use of phosphoric acid as a solvent and the use of formaldehyde which is classified as CMR. The yield obtained after recrystallization was $88 \%$. These phenols were epoxidized by a glycidylation reaction to give a diepoxy (TMBPFE), which has been cross-linked with diaminodiphenylmethane (MDA).<smiles>COc1cc(C(c2ccccc2)c2ccco2)cc(OC)c1OC(=O)OC(=O)Oc1ccccc1</smiles>

(A)<smiles>Cc1cc(Cc2cc([N+](=O)[O-])c(OCC3CO3)c([N+](=O)[O-])c2)cc(C)c1OCC1CO1</smiles>

(B) - TMBPFE<smiles>Cc1cc(-c2cc([N+](=O)[O-])c(OCC3CO3)c([N+](=O)[O-])c2)cc([N+](=O)[O-])c1</smiles>

(C) - TMBP<smiles>COc1cc(Cc2cc(OCC3CC(=O)OC3=O)c(OC)cc2C)c(C)cc1OCC1CC(=O)OC1=O</smiles><smiles>CCCCc1nc(C)nc(Oc2cc(C(C)C)c(Cc3cc(C)c(OC)cc3C(C)C)cc2C)n1</smiles>

(F)

Scheme 3: Structures of thermoplastic polymers and the monomers used to synthesize thermoset materials. ${ }^{53-58}$ 
The authors have studied the effect of the methylene bridge on the thermo-mechanical properties of the materials by comparing the previously synthesized material (from TMBPFE) to the one obtained after the straight C-C aromatic coupling (from TMBP) (Scheme 3-(C)). The amount of each epoxy had been varied and it was shown that the more TMBP in the mixture, the higher the $T_{g}{ }^{54}$ The thermal stabilities were equivalent to those without TMBP. In fact, TMBP brings stiffness to the material thanks to the biphenyl moiety.

The group of Zhao has prepared dicarbonate monomers by an epoxidation reaction of the bisphenol obtained from creosol and formaldehyde, and a cycloaddition of $\mathrm{CO}_{2}$ onto the epoxy ring (Scheme 3(D)). ${ }^{55}$ The use of $\mathrm{BnEt}_{3} \mathrm{NCl}$ instead of TBAB allows the diepoxy to be obtained at a high yield of $84 \%$ with only traces of the monoepoxy moiety. Even if the cycloaddition of carbon dioxide is a very clean reaction which is considered as green, the use of formaldehyde in the previous steps makes limits the environmental interest of the comprehensive monomer synthesis. Subsequently, the cyclocarbonate monomer was used for the synthesis of linear polyhydroxyurethanes (PHUs) by reaction with diamine hardeners (HMDA or IPDA). The thermal properties of these thermoplastic polymers were compared to those obtained from BPA. It has been shown that the glass transition temperatures were higher when the bio-based phenol was used.

The work of Meylemans can also be cited on the coupling of creosol..$^{56-58}$ These authors have studied the catalyst used for this coupling reaction and have shown that the catalyst was involved in the selectivity of the reaction. If a Lewis acid was used $\left(\mathrm{Zn}(\mathrm{OAc})_{2}\right)$, the ortho position was favored because of a chelating effect between the metal, the carbonyl function, and the hydroxyl group (Figure 9). On the contrary, the use of a Brønsted acid favored the meta position. These monomers were used to form polycyanurate thermoset materials. Once again, the presence of methoxy groups reduced the thermal properties of these materials. Finally, the authors have mentioned that the resins could eventually be recyclable with the release of phenol, $\mathrm{CO}_{2}$ and $\mathrm{NH}_{3}$.

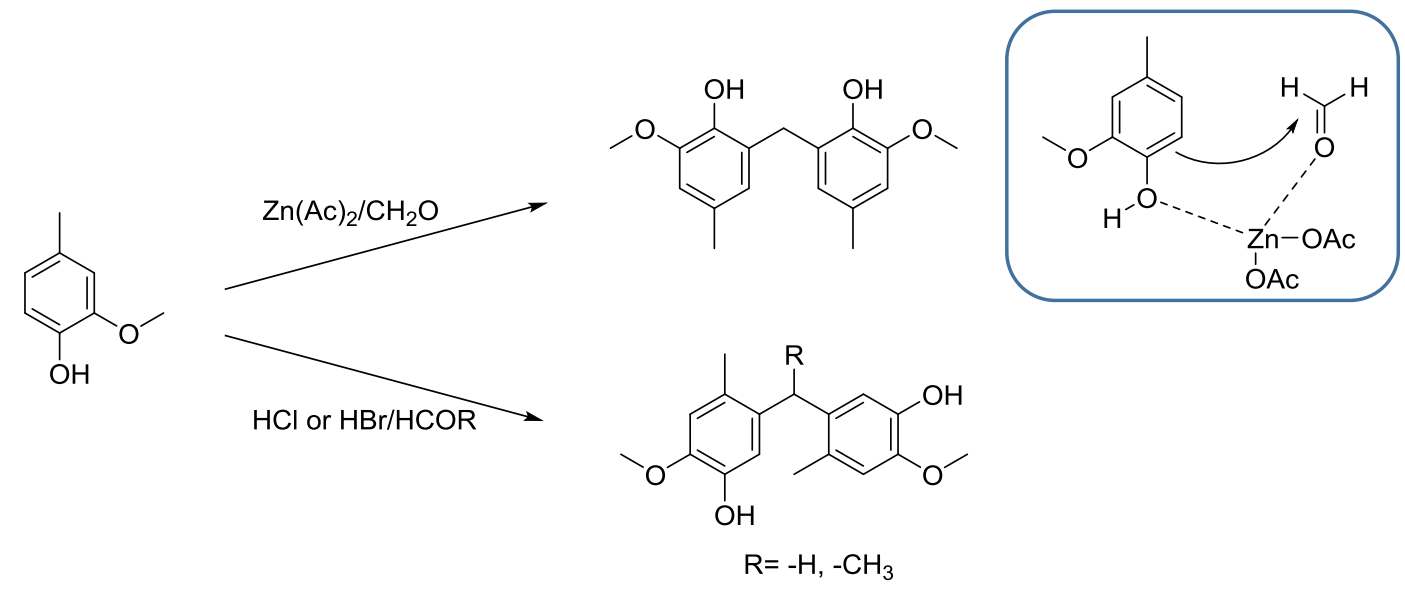

Figure 9: Synthesis of bisphenols by cresol coupling in an acidic medium. ${ }^{56-58}$ 
The group of Zhao has prepared fully bio-based polyphenols from guaiacol or pyrogallol, and 4hydroxybenzaldehyde, vanillin, or syringaldehyde (Figure 10)..$^{59,60}$ It is a formaldehyde-free synthesis and the only drawback is the use in excess of the guaiacol or the pyrogallol which can be evaporated. The effect of the presence of methoxy groups on the monomers and material properties was widely studied. Regarding the monomers, the presence of methoxy reduces the melting temperatures and the conversions. These results could be explained by different manner: the steric hindrance, the spread of the electron density over multiple sites and finally by the formation of hydrogen bonds. After the epoxydation reaction, these monomers were cross-linked by the diethylene triamine (DETA) to give thermosets materials derived from lignin. Furthermore, the presence of methoxy groups have a drastic impact on the thermo-mechanical properties of the resins $\left(T_{g}, T_{\alpha}, E_{\text {glassy }}^{\prime}\right.$ and $T_{d}$ decreased).

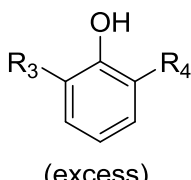

(excess)

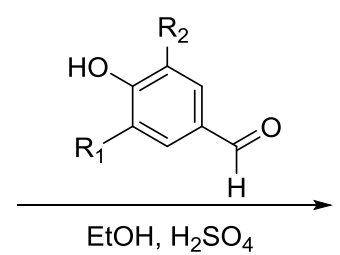

$\mathrm{EtOH}, \mathrm{H}_{2} \mathrm{SO}_{4}$

(1)

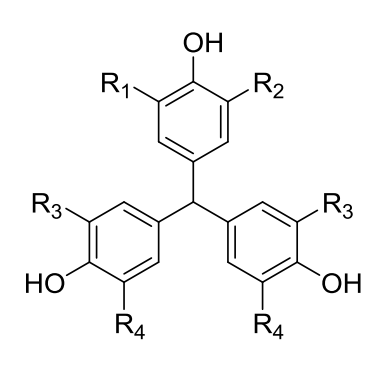

$\mathrm{Rn}=\mathrm{H}$ or OMe $5 \mathbf{- 6 9 \%}$

Figure 10: Synthesis of triphenols by condensation of aldehydes onto phenol derivatives. ${ }^{59,60}$

A lot of dimers have been synthesized and then used to form thermoplastic or thermoset polymers. Some examples of these applications are resumed in the Scheme 3.

The group of Wadgaonkar has coupled guaiacol and syringol, both originating from lignin, with furfural to give fully bio-based bisphenols by basic catalysis. ${ }^{53}$ This synthesis is totally green. Indeed, it is a solvent-free process, using only $5 \mathrm{wt} \%$ of catalysis which only releases water. Yields after precipitation ranged from 55 to $80 \%$. These monomers were used to synthesize polyesters by polycondensation of the phenol moieties onto diacyl chlorides (Scheme 3-(A)). The main advantage of these polymers is that the pendant furan groups could be easily chemically modified.

The group of Harvey has synthesized a bisphenol from carvacrol in water, a mono-terpenic phenol coming from terebenthine and trioxane, which is an in situ source of formaldehyde. ${ }^{61}$ Only the parapara isomer was isolated because of the steric hindrance. A linear polycarbonate was obtained by reaction of hydroxyl groups onto the diphenylcarbonate (Scheme 3-(E)). Furthermore, a thermoset resin was synthesized, first by transformation of the phenol groups in cyanate esters, followed by a cyclotrimerization to create a cross-linked network (Scheme 3-(F)). They have shown that resins 
coming from carvacrol were less likely to capture water than those from classical cyanate esters thanks to the aliphatic substituents.

The work of Stanzione et al. should be mentioned. They have prepared phenolic derivatives bearing a methylene bridge without using formaldehyde, which is an obvious originality. ${ }^{62}$ This synthesis was done in bulk, with an excess of guaiacol which was removed via reduced pressure distillation. Actually, this group has used methylols, obtained by the reduction of the aldehyde function of vanillin, which reacted with phenols, such as guaiacol, to form a dimer (Figure 11). The bisphenol was obtained, after evaporation of the guaiacol in excess, with a yield of $70 \%$.
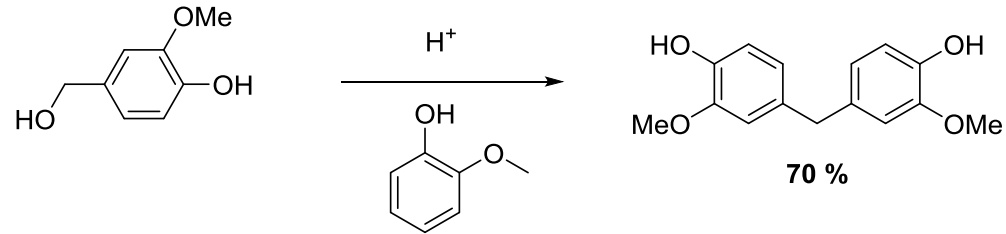

Figure 11: Synthesis of bisphenols from guaiacol and reduced vanillin. ${ }^{62}$

The authors have noted the presence of isomers formed during the electrophilic aromatic substitution. The major product obtained was the isomer which was in the para position of the hydroxyl function (82\%). However, the isomers in the ortho and meta positions of the hydroxyl function were obtained with a very low yield of $3 \%$ for each isomer. These hydroxyl functions were then transformed into epoxy functions, cross-linked with amicure (HDI trimer), and compared to other resins coming from DGEVA for example. The thermo-mechanical properties of the resin coming from guaiacol were comparable to the other resins.

A similar work have been made by the group of Epps. ${ }^{63}$ They prepared ten different bisguaiacols, starting from guaiacol and hydroxybenzylalcohol by acid catalysis (Amberlyst 15). Once again, the phenols are used in excess and evaporated. Furthermore, the loading of catalysis is high (30 wt\%) but it can be easily removed by filtration and recycled. Then, bisguaiacols were functionalized with glycidyl groups and cured with a diamine (MDA). Only few oligomerization was observed by ${ }^{1} \mathrm{H}$ NMR and SEC analyses. Furthermore, the melting temperatures of epoxidized monomers can be altered for desired applications. The thermal and thermo-mechanical properties of these thermoset materials were compared to those of the BADGE-based materials. High thermal properties materials were obtained $\left(\mathrm{T}_{\mathrm{g}}>100^{\circ} \mathrm{C}, \mathrm{T}_{\mathrm{d} 5 \%}>300^{\circ} \mathrm{C}\right)$, similar to those of a petroleum-based material. 


\section{Aromatic and pseudo-aromatic derivatives with ketones coupling}

\section{$\underline{\text { reactions }}$}

\section{a. Use of phenolic derivatives}

The same methodology used for aldehyde was applied to ketones. Gross et al. have coupled phenol to levulinic acid and obtained, after esterification, the products described in Figure $12-(2) .{ }^{50}$ The yields of the esterification reaction were very high (from 85 to $90 \%$ ). However, this reaction required the use of a very large excess of phenol which is classified as CMR. The bisphenols obtained were epoxidized using epichlorohydrin which is also a compound classified as CMR and cross-linked with IPDA. The main point of interest of this synthesis was that the obtained epoxies were liquid, due to the presence of the ester function. Thus, the processability of the epoxy was improved. Furthermore, depending on the substituent, the viscosity of the monomer can be controlled (792 Pa.s for OMe against 12 Pa.s for OPent). However, these thermoset materials didn't show improved thermomechanical properties except for the $T_{g} S$, which considerably decreased when the chain length increased $\left(158^{\circ} \mathrm{C}\right.$ for OMe and $86^{\circ} \mathrm{C}$ for OPent).

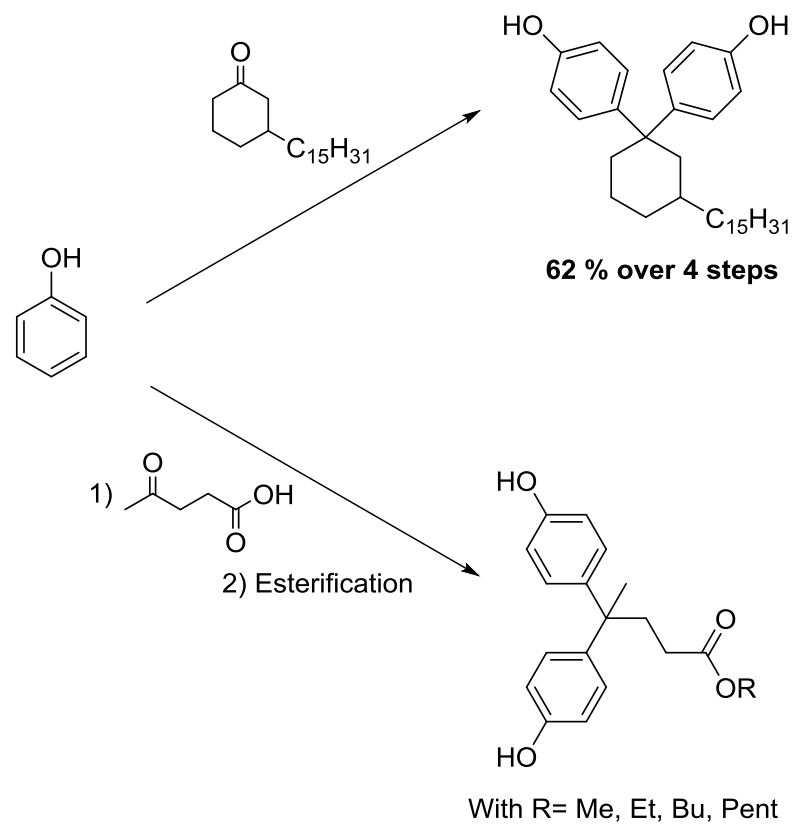

Figure 12: Dimers obtained from phenol and various ketones. ${ }^{50,64}$

Another ketone group, prepared by the group of Wadgaonkar and synthesized from cardanol, allows the coupling reaction of two phenol compounds (Figure 12-(1)). ${ }^{64}$ After two successive reductions of the unsaturations of the aliphatic chain and of the aromatic, and oxidation of the secondary hydroxyl function, the ketone was obtained. It was subsequently coupled to phenol to obtain a dimer with an overall yield of $62 \%$ over four steps. Even if the ketone used is fully bio-based, a large excess of phenol is used and anhydrous hydrogen chloride gas is present in the system. 


\section{b. Use of furanic derivatives}

2-Furoic acid has been used many times to synthesize bio-based dimers. Actually, this acid, coming from the oxidation of furfural, allows dimers to be obtained by a coupling reaction with acetone (Figure 13). ${ }^{65}$ These diols, obtained after reduction of the ester functions, were epoxidized with an overall yield of $40 \%$ over four steps. This synthesis requires many steps including a protective reaction of the carboxylic acid which does not respect the atom efficiency or the green chemistry principles. A study was done on the photo-curing of these species and the properties of the materials were compared to those obtained from a petrosourced adhesive (phenylglycidylether). The tensileshear strength of PC joints were lower for the bio-based material in comparison. The authors explained that these results were due to the stiffness of these materials and their hydrophobic properties.
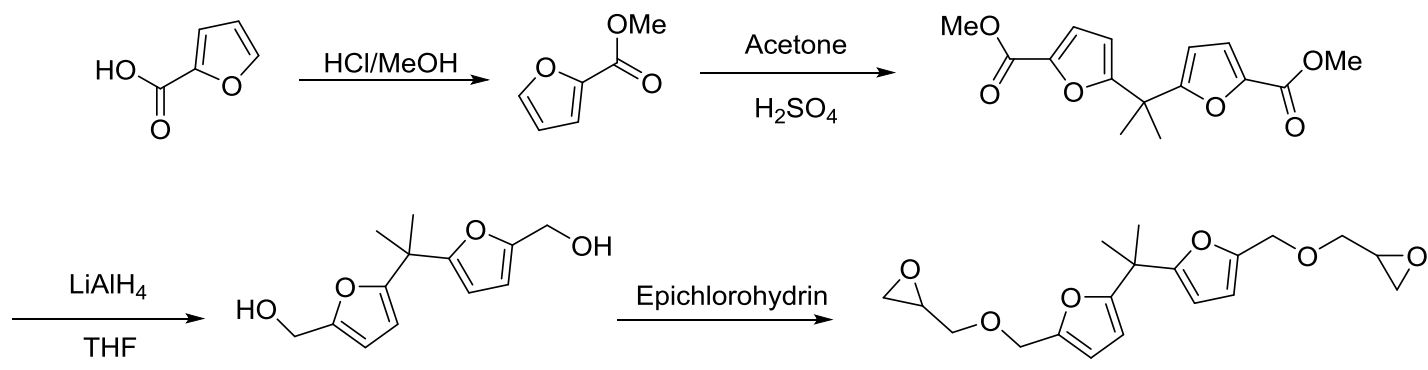

$40 \%$ over 4 steps

Figure 13: Synthesis of diols by furoic acid and acetone coupling reaction. ${ }^{65}$

The SIKA enterprise has prepared diamines by a coupling reaction of furfuryl amine with acetone with a low yield $(31 \%) .{ }^{66}$ These diamines were cross-linked with epoxies (similar to BADGE) to form materials with low volatile organic compounds (VOCs).

To summarize, this coupling methodology has been used extensively to prepare bisphenols and bisfurans, largely substituted by various alkyl or alkyl ether groups, with a methylene bridge substitute in various positions.

\section{Esterification or trans-esterification reactions using enzymes}

The group of Allais reported interesting enzymatic trans-esterification reactions. ${ }^{67}$ These syntheses totally respect green chemistry principles. Indeed, the only released product during synthesis is ethanol. First, the unsaturation of ferulic acid is reduced by hydrogen. In fact, it has already been shown that the presence of this unsaturation lengthens the reaction time or decreases the yields. Furthermore, CAL-B enzyme, which is inactive towards the phenol function, allow selective transesterification, without any by-product. Hence, the protection of these functions is not necessary. Moreover, the authors have shown that two different transesterification procedures can 
be performed. The first one is a solvent free reaction under reduced pressure and the second one uses hexane with azeotropic removal of ethanol. In both cases, yields are above $85 \%$ (Figure 14). These polyols were functionalized to give the corresponding acrylates or allyl ethers. However, no polymers were synthesized with these monomers.

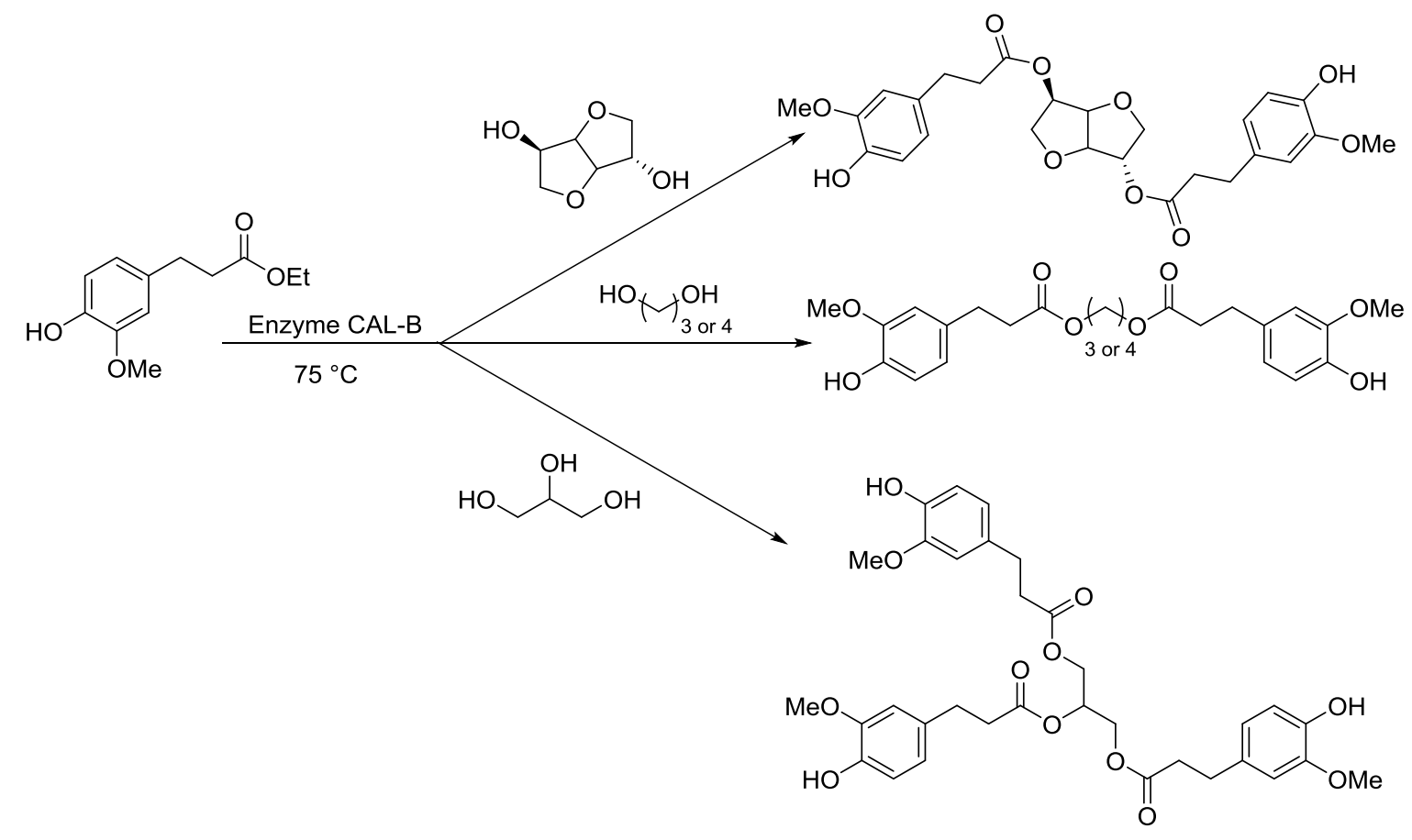

$85-95 \%$

Figure 14: Transesterification reaction from hydrogenated ferulic acid.

Then, they extended their methodology to synthesize a library of saturated and unsaturated bis- and tri-phenols derived from $p$-hydroxycinnamic acid. ${ }^{68}$ They have shown that these compounds are potential antioxidants. Moreover, Gross et al. studied the biosynthesis of pentagalloylglucose to lead to gallotannins and ellagitannins. ${ }^{69}$ The pentagalloylglucose is synthesized from gallic acid using first the UDC-glucose to form the $\beta$-glucogallin which act as a donor-acceptor of acyl group (Figure 15). Once again, this synthesis totally respects the green chemistry principles.

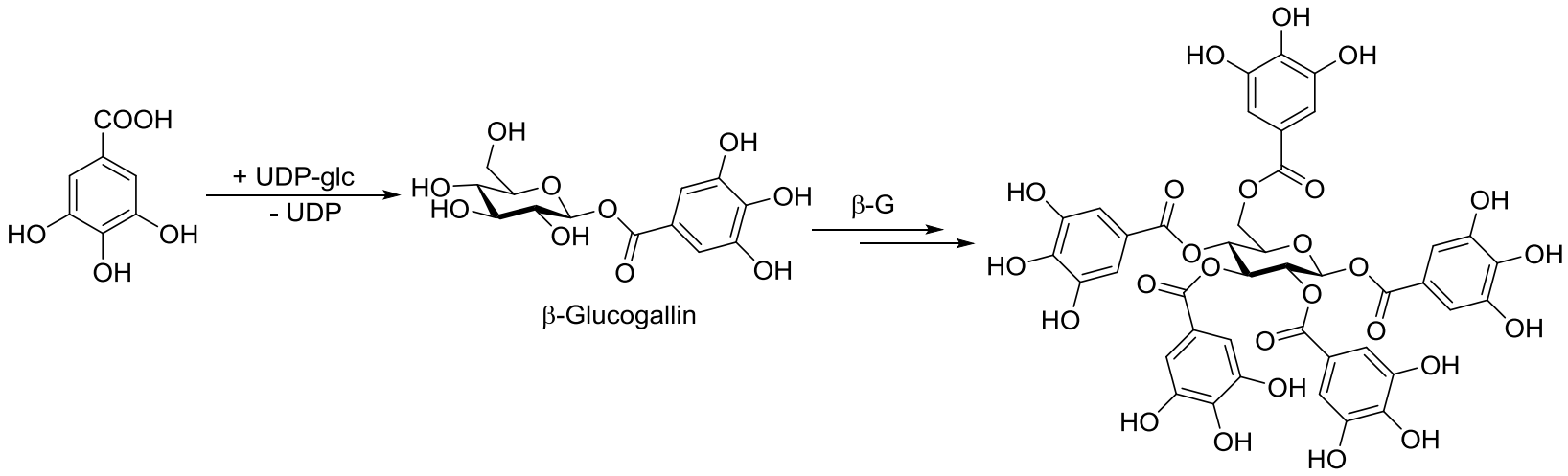

Figure 15: Synthesis of pentagalloylglucose. 


\section{Reductive coupling of aldehydes}

The inter-aldehyde coupling, commonly named pinacol coupling, leads to the creation of a carboncarbon bond between two aldehydes and to the formation of vicinal diols using metallic catalysis. These coupling reactions can be performed chemically with reactions, such as McMurry type, or electrochemically.

\section{McMurry type coupling reaction}

The group of Duan has used a combination of $\mathrm{TiCl}_{4}-\mathrm{Mn}$ to generate in situ a low-valent titanium for a cross-coupling reaction between benzaldehyde and vanillin (Figure 16:16). ${ }^{70}$ The yield of the reaction was $64 \%$, after purification by column chromatography, and the enantiomeric excess was 76:24 in favor of the erythro diastereoisomer. However, products from the homocoupling reaction have been detected, but the proportions obtained were not discussed.
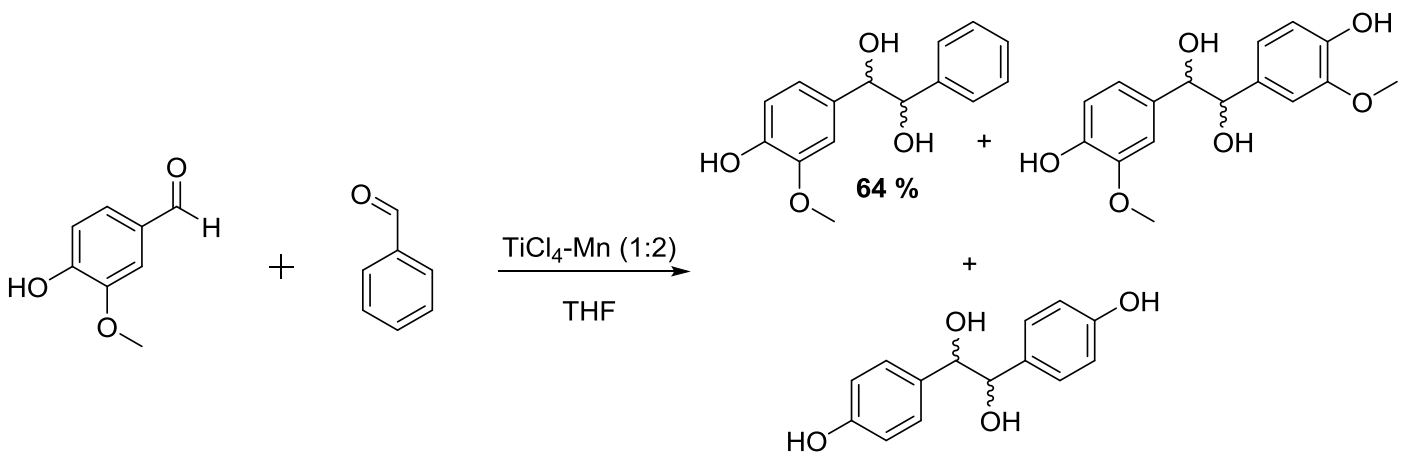

Figure 16: Synthesis of vicinal diols. ${ }^{70}$

Li et al. have used magnesium powder under ultrasound to obtain a vanillin dimer with a yield of 51 $\%$, but the vanillic alcohol was also obtained with a yield of $8 \%{ }^{71}$ This procedure is greener than the previous one. Indeed, the catalyst is non-toxic and no solvent is needed.

The vicinal diols formed could be deoxygenated to form an alkene following the reaction described by McMurry by a thermal effect. ${ }^{72}$ Hence, the group of Mukaiyama realized a study on various aldehydes and ketones using a combination of zinc and $\mathrm{TiCl}_{4}$. They studied the gem diol/alkene selectivity depending on the reaction conditions ${ }^{73}$ and have shown that the reaction temperature had a major impact on the selectivity. In fact, the homocoupling of benzaldehyde, which was performed in $\mathrm{THF}$ at $0^{\circ} \mathrm{C}$, only gave the gem diol while the alkene was obtained quantitatively in dioxane at reflux.

Finally, Harvey et al. have applied this reaction to vanillin to form bio-based bisphenols (Figure 17:17). ${ }^{74}$ Two kinds of monomers could be obtained after the transformation of the hydroxyl groups 
into cyanate esters: one that retains the unsaturations and one that is reduced by dihydrogen. These monomers were cross-linked by homopolymerization and the effect of the double bond on the properties of the materials were investigated. It was shown that the thermal properties were reduced for the material that came from the alkene monomer. It should be noted that the authors also mentioned a patent which discussed equivalent epoxies. ${ }^{75}$

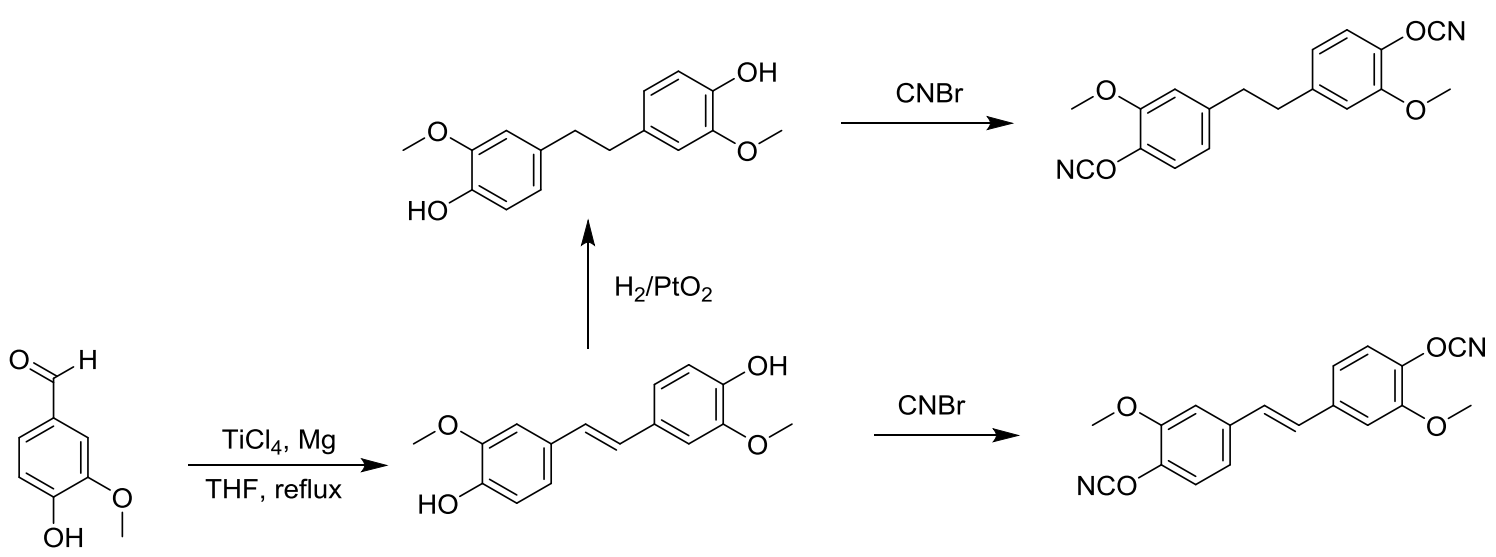

Figure 17: Coupling of the aldehyde function of the vanillin for the synthesis of diols. ${ }^{74}$

The McMurry reaction is a reaction allowing the obtention of vicinal diols but not owing to green way. Indeed, stoichiometric $\mathrm{TiCl}_{4}$ is needed in this reaction. This strong Lewis acid substance is hazardous due to the release of hydrogen chloride. Greener routes to obtain vicinal diols can be obtained by electrochemistry.

\section{Electrochemical coupling}

The electrochemical method, developed in 1952 by Pearl, ${ }^{76}$ is the most commonly used method and has been applied in various domains. This methodology allows hydrovanilloine (I) to be obtained with a yield of $80 \%$ (Figure 18). This compound was oxidized in diketone (II), reduced in monoketone, and finally reduced in alkene using Raney nickel.<smiles>COc1cc(C(=O)c2ccc(C(=O)c3ccc(OC)c(OC)c3)cc2OC)ccc1O</smiles><smiles>COc1cc(/C=C/c2ccc(O)c(OC)c2)ccc1O</smiles> 
Figure 18: Synthesis of bisphenols from vanillin using the Pearl method. ${ }^{76}$

Formophenolic resins have been prepared by the group of Amarasekara, synthesized electrochemically from vanillin dimer. A yield of $86 \%$ was obtained without purification, with the dimer being composed of $94 \%$ of meso compound (the amount of meso compound depends on the current density). The obtained dimer was then reacted with formaldehyde in basic medium to give the resulting polymer resin. The authors have shown that the polymers obtained had a better quality control possibilities in comparison to lignin-formaldehyde resins (Figure 19). ${ }^{77}$

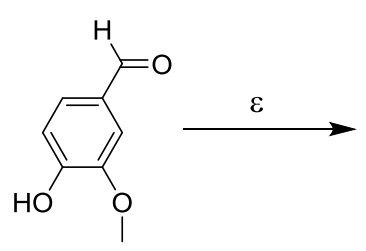

Figure 19: Synthesis of meso-hydroxyvanilloin-formaldehyde polymer. ${ }^{77}$

Finally, Harvey's group synthesized stilben derivatives from vanillin. ${ }^{74}$ They first wanted to adapt the Pearl method, however the deoxygenation didn't give the expected results (using $\mathrm{PtO}_{2}$ ) and this was explained by the lack of solubility of the reactant. In order to improve this solubility, the tetra-acetate was synthesized and reduced using a base and zinc (Figure 20). However, it is not really efficient in terms of atom economy. They have shown that the deoxygenation mechanism included the formation of an epoxy intermediate which was reduced by the zinc. The authors have noted that the use of the coupling conditions of $\mathrm{McMurry}\left(\mathrm{TiCl}_{4} / \mathrm{Mg}\right)$ allowed the synthesis to be straighter and to obtain a better yield (46\% using the McMurry method against $23 \%$ by electrochemical synthesis over three steps.)<smiles>COc1cc(C2OC2c2ccc(OC)c(C3OC3C(=O)CO)c2)ccc1OC(C)=O</smiles><smiles>COc1cc(/C=C/c2ccc(O)c(OC)c2)ccc1O</smiles>

Figure 20: Proposed mechanism for the elimination of vicinal diols using basic catalysis. ${ }^{74}$ 


\section{Aldolisation/crotonisation reactions}

\section{Use of phenols}

In 1954, Rumpel carried out an aldolisation reaction followed by a crotonisation reaction from vanillin and cyclohexanone. ${ }^{78}$ The structures obtained after these reactions are similar to those of curcumin.

The benefits of curcumin (anti-inflammatory, antioxidant, hypotension, antibacterial, hypocholesterol) have motivated the researchers to study this reaction. Vandergoot et al. have prepared, in 1997, various compounds from vanillin or syringaldehyde (Figure $21-(1),(2)$ and (3)) ${ }^{79}$ with yields varying from moderate (43\%) to quantitative depending on the substituent. These syntheses are fully green. Indeed, the solvent used is water, which is also the only released product. These molecules are potential analogues of curcumin. In fact, they have been tested for the inhibition of the peroxidation of lipids. The biological activities of these molecules have shown some success but no polymer has been described.

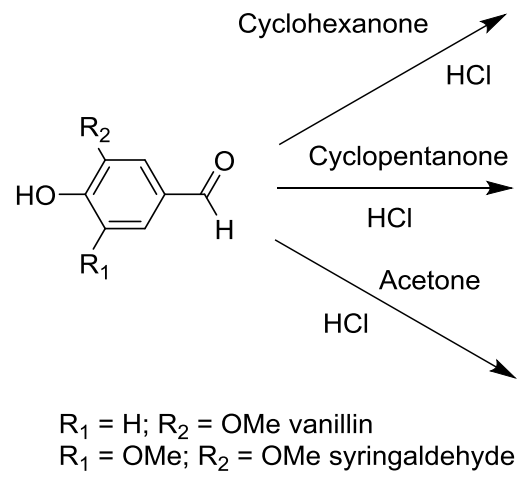<smiles>[R]c1cc(/C=C2\CCC/C(=C\c3cc([R])c(O)c([R])c3)C2=O)cc([R])c1O</smiles><smiles>[R]c1cc(/C=C2\CC/C(=C\c3cc([R])c(O)c([R])c3)C2=O)cc([R])c1O</smiles><smiles>[R]c1cc(/C=C/C(=O)/C=C/c2cc([R])c(O)c([R])c2)cc([R])c1O</smiles>

Figure 21: Aldolisation/crotonisation reactions between vanillin or syringaldehyde and aliphatic ketones. ${ }^{79,80}$ These reactions were also studied by the group of Samui. ${ }^{80}$ Bio-based phenols were synthesized from vanillin or syringaldehyde with good yields from 65 to $78 \%$ (Figure $21-(1)$ and (3)). These dimers were epoxidized and carboxylic acids with different functionalities (2 or 3) were used to open the epoxy ring. The addition of trimesic acid on these epoxy moieties allowed cross-linked polyesters to be obtained. On the other hand, the use of terephthalic acid allowed the synthesis of a thermoplastic polymer. These polymers, which bear bisbenzyliden groups, can be used as photoactive liquid crystalline polymers. 
More recently, Shibata et al. have carried out a similar synthesis using vanillin and cyclohexanone to obtain bisphenols, which were epoxidized (DGEDVCP). ${ }^{81}$ This time, the solvent used was dioxane, which is a CMR compound. They have been cross-linked using quercetin (QC) or novolac guaiacol (GCN), which are bio-based crosslinking agents, and compared to materials from BADGE. The $5 \%$ degradation temperatures were lower for the bio-based material while the char yields were higher. These bio-based dimers could replace the conventional petrosourced resins.

\section{Use of furans}

The aldol condensation has been known for a long time for producing the furan moiety. Gandini et al. have described these works in their book on furan. ${ }^{7}$ When an excess of furfural was used, difurfuryliden derivatives were obtained (Figure 22). The latter can be polymerized, by anionic polymerization, using a base ( $n$-BuLi, $t$-BuOK...) to give polymers with low molecular weight. ${ }^{82}$

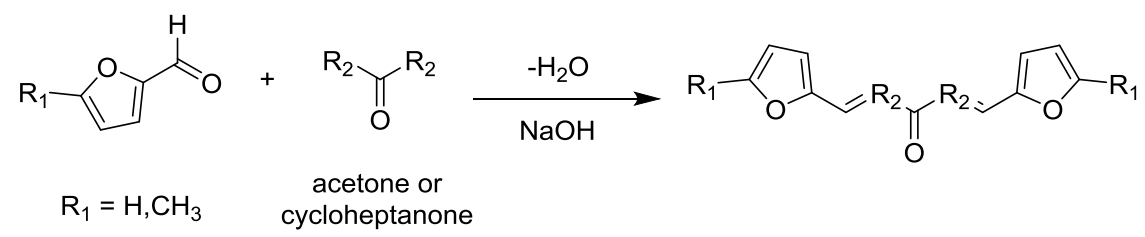

Figure 22: Condensation reaction of furfural and various ketones.

The group of Al-Muaikel has studied the condensation of furfural with cycloheptanone. ${ }^{11}$ This dimer was obtained with an almost quantitative yield of $95 \%$ and was functionalized with diacyl chloride reagents by a Friedel-Kraft reaction in order to synthesize polyketones. These polymers have shown good thermal properties for aliphatic ketones. Furthermore, antimicrobial properties were obtained.

Similarly, Gandini et al. have carried out this kind of reaction by a condensation reaction of malonic acid on 5 -formylfurfural to give the corresponding diacid with a yield of $70 \%$ after recrystallization (Figure 23). ${ }^{83}$ The synthesis of this diacid is performed in pyridine which is a very harmful substance and classified as potentially CMR. These monomers have been photopolymerized to give a cyclobutane polymer.

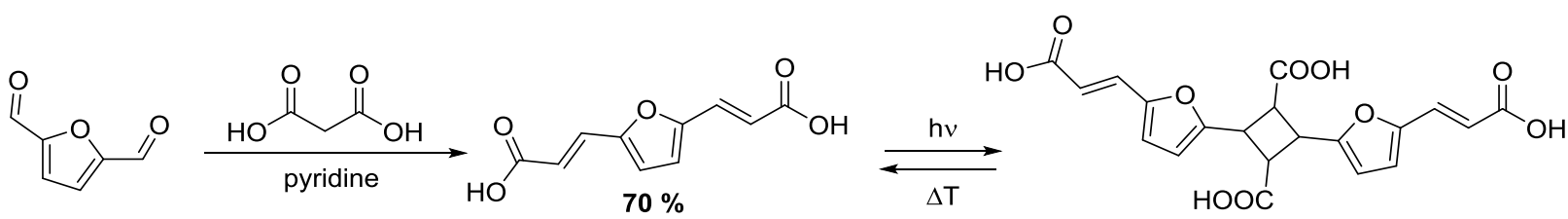

Figure 23: Synthesis of diacid by malonic condensation of 5-formylfurfural. ${ }^{83}$

More recently, the group of Wang carried out the coupling of furfural with cyclic ketones using various supported reagents $\left(\mathrm{KF}-\mathrm{Al}_{2} \mathrm{O}_{3}, \mathrm{~K}_{2} \mathrm{CO}_{3}-\mathrm{Na}_{2} \mathrm{CO}_{3} \ldots\right)$ under microwave irradiation with a reaction 
time of under 5 minutes to obtain yields above $80 \% .{ }^{84}$ One of the most interesting aspect of this work is that the catalyst can be reused. That is why this reaction can be considered as fully green.

In 2008, Dumesic et al. have studied the coupling of hydroxymethylfurfural (HMF) with various aliphatic ketones in a biphasic medium. ${ }^{85}$ Various reaction parameters have been studied such as the acetone/HMF, $\mathrm{NaOH} / \mathrm{HMF}$ ratios, or the temperatures. All of these reaction conditions have an effect on the ratio of mono or double condensation.

The target application is biofuels from polysaccharides. Since 2008, Dumesic et al. have studied the transformation of polysaccharides into liquid alkanes. ${ }^{86}$ Their process involved an acid catalysis as a first step to convert the polysaccharide in HMF. A subsequent aldolisation/crotonisation reaction was performed with aliphatic ketones, then two steps of successive hydrogenation allowed the liquid alkanes to be obtained with a chain length of 7 to 15 carbons (Figure 24). The overall yield was $65 \%$ over four steps.

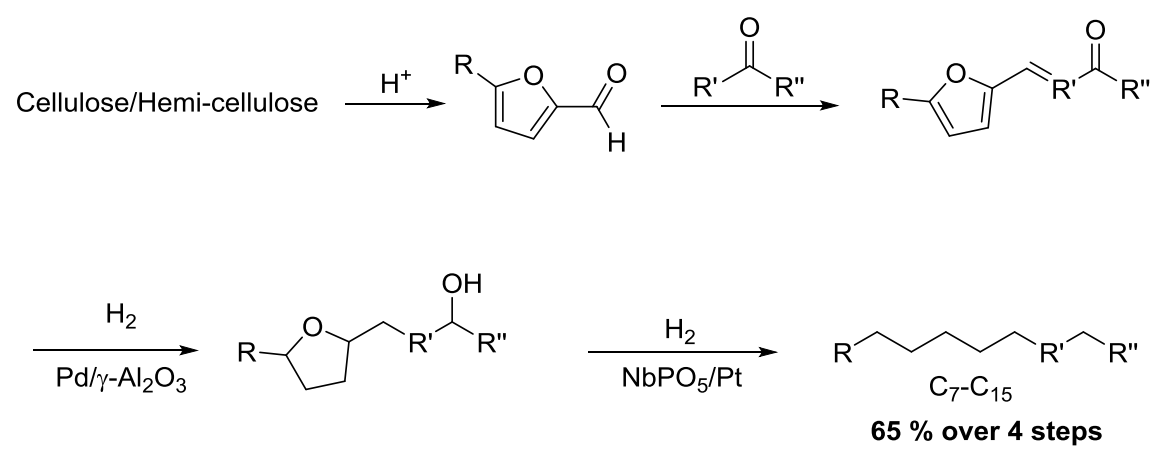

Figure 24: Synthesis of liquid alkanes. ${ }^{86}$

More recently, the group of Zhang continued the work on the conversion of polysaccharides into biofuel. They have transformed, in a one-pot reaction, cellulose or hemicellulose in furfurlidene by catalysis with a metal chloride $\left(\mathrm{NiCl}_{2}, \mathrm{CoCl}_{2} \ldots\right)$ with a yield of $44 \% .{ }^{13}$

One last work to present on this subject is the reactivity of $\alpha, \beta$-unsaturated ketones with amines and anhydrides (Figure 25). ${ }^{87}$ The authors have first synthesized a mono and a di-furfurylidene by reaction of acetone on furfural. They have shown that the reaction of these monomers with amines (diethylenetriamine) worked while the anhydride (iso-methyltetrahydrophthalic anhydride) was inactive. Concerning the amine, the authors have demonstrated that the secondary amine added first in the 1,4 position, then the primary amine formed a Schiff base by reacting with the resulting carbonyl. These results allowed the calculation of the exact ratio of cross-linking agent needed to form a resin. 


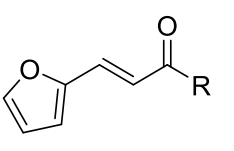

$\mathrm{R}=\mathrm{Me}$ or dimer

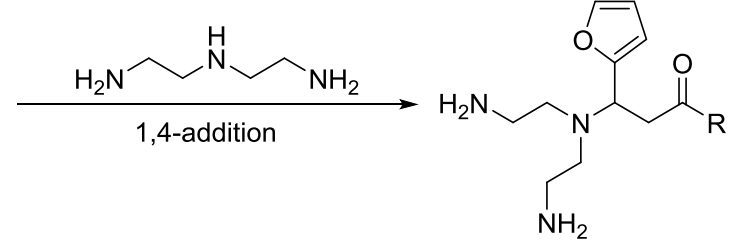

$\mathrm{NH}_{2}$

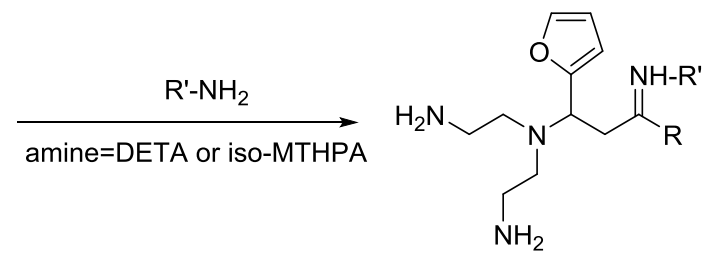

Figure 25: Addition of an amine on a $\alpha, \beta$-unsaturated ketone. ${ }^{87}$

The aldolisation/crotonisation reactions allow the easy formation of dimers in a green way depending on the experimental conditions. Indeed, most of the time, the reactants used could be replaced by safer compounds.

\section{Coupling of aromatic compounds by metathesis}

The self-metathesis and cross-metathesis of eugenol have been studied many times by the group of Harvey ${ }^{88,89}$ In fact, they have prepared, after metathesis and hydrogenation of the double bond, bisphenols used to synthesize cyanate resins (Figure 26). The yield of the metathesis reaction was 93 $\%$ and the materials obtained were high performance thermosets with good thermo-mechanical properties. Furthermore, these resins could possibly be recycled by a controlled pyrolysis process. The metathesis reaction does not need the use of a solvent and the ruthenium catalyst could be recycled.<smiles>C=CCc1ccc(O)c(OC)c1</smiles>

Figure 26: Synthesis of cyanate ester resins from eugenol by self-metathesis. ${ }^{88,89}$ 


\section{Coupling of pseudo-aromatic compounds by etherification}

The OBMF (5,5'(oxy-bis(methylene))bis-2-furfural) was prepared from HMF using organic acids as catalyst. There are various methods of synthesis of these dialdehydes but two kinds of catalyses are predominant. The first one requires the use of organic acid and in particular, the Amberlyst 15 (Figure 27). Trabelsi et al. have shown that the addition of ultrasound significantly increased the reaction yield with the use of dichloromethane (96 \% yield). ${ }^{90}$ The only released product is water and the catalyst can be recycled but the solvent used is dichloromethane, a CMR substance.

2<smiles>O=Cc1ccc(CO)o1</smiles><smiles>O=Cc1ccc(COCc2ccc(C=O)o2)o1</smiles>

$96 \%$

Figure 27: Coupling of HMF for the synthesis of bismethylfurfuraldehydes oxide..$^{90}$

The second one, a more recent method, involves inorganic catalysts. The group of Corma, in 2010, has studied this etherification reaction via the use of catalysts, such as zeolite in specific solvents, and yields of up to $99 \%$ have been obtained. ${ }^{91}$ More recently, Rode et al. have described the etherification of HMF using a tin catalyst, montmorillonite, and apolar solvents with very good yields of up to $98 \% .^{92}$ This catalyst is particularly interesting because it contains both a Brønsted acid $\left(\mathrm{Sn}(\mathrm{OH})_{4}\right)$ and a Lewis acid $\left(\mathrm{Sn}^{4+}\right)$. The main inconvenience of this reaction is that the water has to be continually removed from the reaction medium to achieve the best possible yield. Furthermore, the catalyst can be recycled but this reaction has to be done in apolar solvents like 4-chlorotoluene to allow highest conversion and regioselectvity.

\section{Coupling of aromatic and pseudo-aromatic compounds by}

\section{formation of a Schiff base}

In the 80s, Dunlop registered two patents on the coupling of the furfuryl alcohol by a Mannich-type reaction from formaldehyde and an amine (Figure 28-(1))..$^{93,94}$ This reaction is a multi-component reaction and involves the formation of an in situ Schiff base. Actually, the furfuryl alcohol is able to add on this strong electrophilic species. In this reaction, the Schiff base was a reactive intermediate. These patents are very short and no applications have been described. 


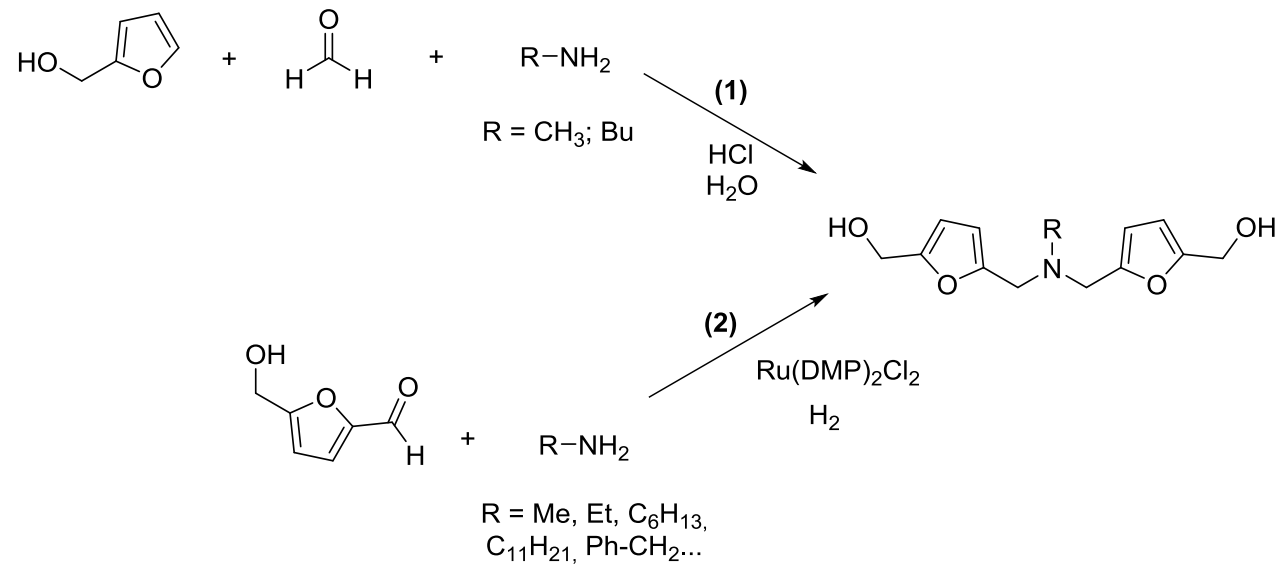

Figure 28: Synthesis of diols from furan derivatives by a Mannich type reaction. ${ }^{79-95}$

Recently, the group of Zhang described the synthesis of related compounds using a method which eliminated the use of formaldehyde, a compound classified as CMR (Figure 28-(2)). ${ }^{95}$ This reaction involved two reductive amination processes using a ruthenium catalyst. Actually, the reduction of a first Schiff base was carried out using dihydrogen. The imine, previously formed by dehydration, was then reduced. The yields were good (from 57 to $88 \%$ ) except when the amine function bore sterically hindered groups, such as tert-butyl groups, or polar groups, such as hydroxyl function. This reaction is greener than the first procedure which used formaldehyde. However, it uses dihydrogen which is hardly usable in the industry due to hazardous handling.

The group of Amarasekara described the synthesis of divanillin by the formation of a Schiff base by reaction of an amine on an aldehyde (Figure 29). ${ }^{96}$ This synthesis allowed the expected dimer to be obtained in quantitative yield without purification. This reaction uses a green solvent but the amine is highly toxic (LD50 of $177 \mathrm{mg} \cdot \mathrm{kg}^{-1}$ ). 


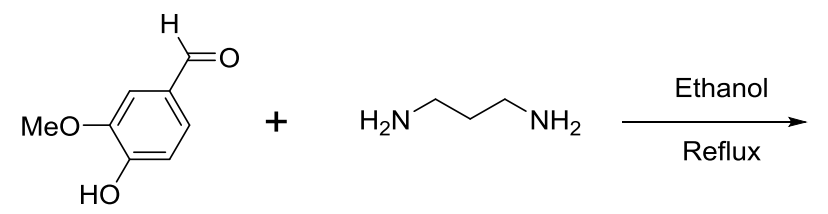<smiles>COc1cc(/C=N/C(C)(C)C)ccc1O</smiles>

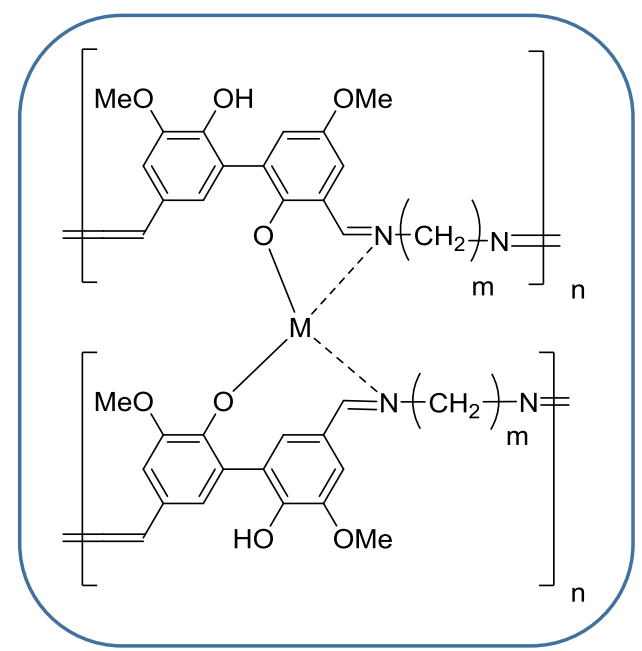

Figure 29: Synthesis of $\mathrm{N}, \mathrm{N}^{\prime}$-bis(vanillidene)-1,3-propanediamine by formation of a Schiff base and their complexation of a metal onto the polymer of divanilline. ${ }^{96}$

This method was then extended to the synthesis of a polymer from a divanillin and a diamine. The authors mentioned that this polymer could be used for metallic ions complexation $\left(\mathrm{Cu}^{2+}, \mathrm{Fe}^{2+}, \mathrm{Co}^{2+}\right)$ in aqueous solution.

\section{Other coupling reactions}

A number of other coupling reactions were carried out using more specific methods which will be detailed in this section.

Many coupling reactions were performed from eugenol because of its double reactivity (phenol and allyl) which are summarized in Figure $30 .{ }^{97-101}$ Various kinds of reactions were used: (A) acylation reaction followed by the epoxidation of the allyl function; (B) substitution reaction followed by the epoxidation of the allyl function; $(C)$ thiol-ene reaction followed by the glycidylation reaction of the phenol function; (D) phosphorylation reaction followed by the epoxidation of the allyl function. All of these monomers have been cross-linked by amine hardeners to give thermoset materials. 
<smiles>COc1cc(CC2CO2)ccc1OCc1ccc(COc2ccc(CC3CO3)cc2OC)cc1</smiles><smiles>C=CCc1ccc(O)c(OC)c1</smiles>

Figure 30: Examples of eugenol coupling. ${ }^{97-101}$

These bio-based thermoset materials were also compared to those coming from a petrosourced epoxy (BADGE). The thermo-mechanical properties of these bio-based resins were either improved or similar compared to those coming from BADGE.

Another innovative coupling reaction was presented by the group of Balamurugan. ${ }^{102} \mathrm{~A}$ condensation of hydrazine on the acid function, catalyzed by polyphosphoric acid, followed by a dehydration gave an oxadiazole (Figure 31). Hydrazine is a CMR substance. After epoxidation of the phenol functions and a cross-linking reaction using aromatic amines, liquid crystalline thermosets were obtained.

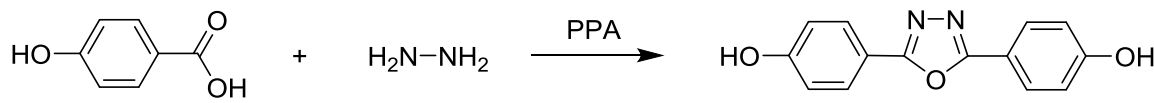

Figure 31: Coupling of phenolic acid with hydrazine to give liquid crystalline thermosets. ${ }^{102}$ 
The group of Livant has studied the coupling of resorcinol and acetone (Figure 32). ${ }^{103}$ This reaction, which have been done in 1982, has been studied many times (publications, patents...). A tetrahydropyrane bearing three phenol functions has been synthesized. For this procedure, a mixture of diethyl ether (extremely inflammable) and dichloromethane (CMR) which are harldly allowed in industry. This compound has been epoxidized in 2007 by Cheng et al. ${ }^{104}$ This triepoxy was crosslinked by an aromatic amine and the materials obtained were compared to those coming from BADGE. The thermal properties were improved for the bio-based material.

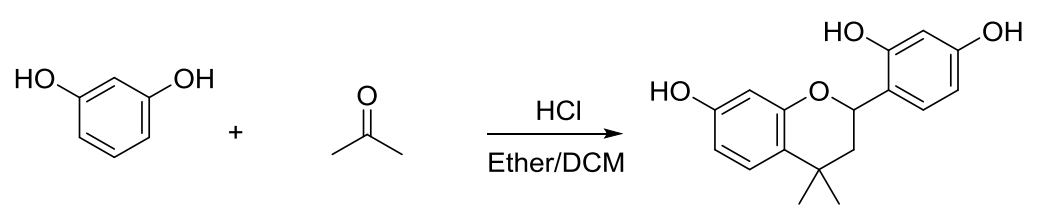

Figure 32: Coupling reaction of resorcinol with acetone. ${ }^{103}$

Other triphenols have been prepared using ketones that are not acetone. Using phorone in the reaction led to a bisphenol which is a spiro compound (Figure 33). This product was obtained with a very good yield of $95 \%$ but no materials were further synthesized from this dimer.

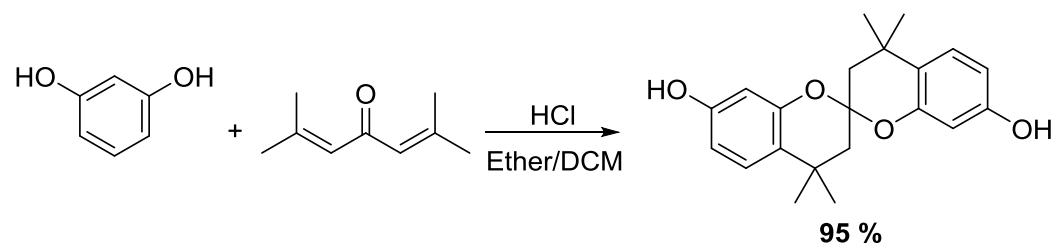

Figure 33: Synthesis of diphenols from resorcinol and phorone. ${ }^{103}$

An original Ugi reaction allowing the synthesis of bis- or triphenols has been performed by the group of Liu (Figure 34). ${ }^{105}$ This reaction involves a carboxylic acid (gallic acid or hydroxybenzoic acid), an aldehyde ( $\beta$-resorcylaldehyde, vanillin or 4-hydroxybenzaldehyde), aniline and an isocyanide. This reaction yields bis-amides with moderate yields between 51 and $74 \%$. The authors have tested their antioxidant ability and have provided novel information on the structure-activity relationship for antioxidant design showing that it depends strongly on the isocyanide moiety.
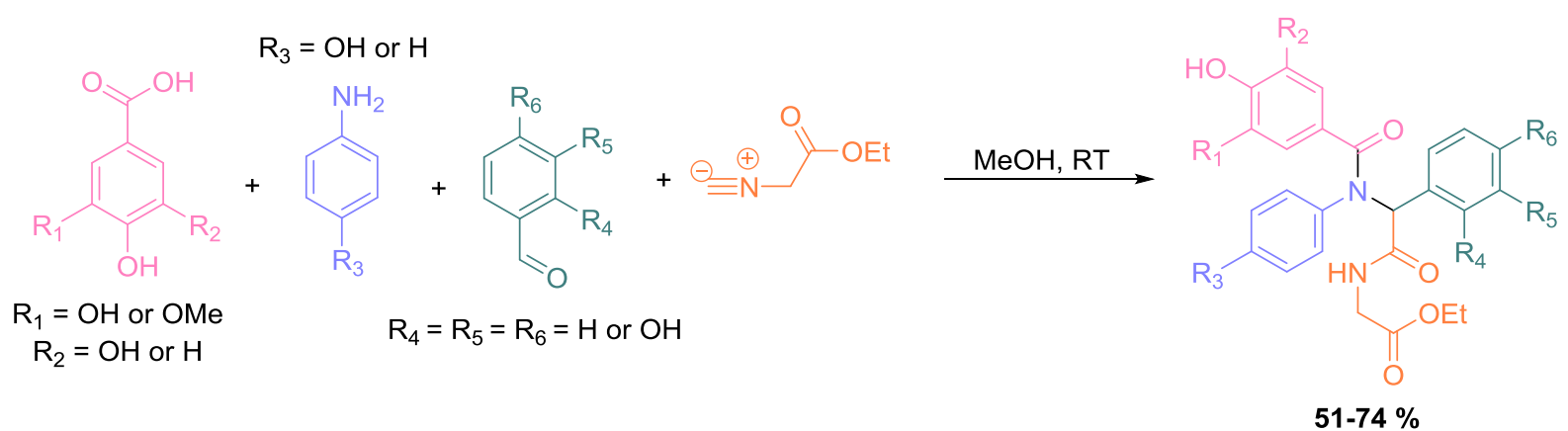

Figure 34: Ugi multicomponent reaction forming bis-amides. 


\section{Conclusion}

The analysis of these results on the coupling of aromatic or pseudo aromatic compounds has been the subject of many publications and patents. This review references only several examples of each reaction, which allows for the synthesis of dimers or trimers and their applications. Some works have been excluded even though they are relevant to the work on organic methodology because the spacers are very large. ${ }^{100}$

Many reactions from traditional organic chemistry have not yet been used to carry out these coupling reactions of organic derivatives. Hence, the metathesis is reported but the Suzuki, Heck, and Mitsunobu reactions are rarely used and remain a goal for researchers. This can be explained by the lack of availability of some building blocks and their polyfunctionality, which complicate their functionalization. Furthermore, only a few syntheses use a fully green process. In fact, only the processes that involve electrochemistry or enzymes are considered fully green. This issue remains crucial for chemical research because of the lack of petrosourced resources. Furthermore, these coupling reactions have a great impact on the chemical stability, the thermo-mechanical properties and the renewable carbon content of the polymer. Moreover, these coupling reactions can be used to form polyfunctional monomers which have less toxicity. For example, the substitution of acetone by acetaldehyde, in the BPA synthesis could lead to a monomer which have a reduced endocrine disruptor effect. ${ }^{106}$ However, the toxicity of most of the synthesized bis- or triphenols is usually not discussed. Indeed, in order to propose a real comparison between BPA derivatives and those monomers, more studies need to be performed.

Finally, all of these coupling reactions could eventually be carried out as part of a biorefinery. The international energy agency defines a biorefinery as "an industrial unit of durable conversion of biomass into a set of commercial products and in energy". In other words, it must be able to synthesize analogues of petrosourced derivatives. Many studies have recently been done, demonstrating a major interest in a biorefinery producing phenolic derivatives from lignin. ${ }^{107,108}$ 
(1) Van Schoubroeck, S.; Van Dael, M.; Van Passel, S.; Malina, R. A Review of Sustainability Indicators for Biobased Chemicals. Renewable and Sustainable Energy Reviews 2018, 94, 115126. https://doi.org/10.1016/j.rser.2018.06.007.

(2) SUn, X. S. OVERVIEW OF PLANT POLYMERS: RESOURCES, DEMANDS, AND SUSTAINABILITY. In Bio-Based Polymers and Composites; Elsevier, 2005; pp 1-14. https://doi.org/10.1016/B978012763952-9/50002-2.

(3) Nadar, S. S.; Rao, P.; Rathod, V. K. Enzyme Assisted Extraction of Biomolecules as an Approach to Novel Extraction Technology: A Review. Food Research International 2018, 108, 309-330. https://doi.org/10.1016/j.foodres.2018.03.006.

(4) Lochab, B.; Varma, I. K.; Bijwea, J. Sustainable Polymers Derived From Naturally Occurring Materials. Advances in Materials Physics and Chemistry 2012, 02 (04), 221-225. https://doi.org/10.4236/ampc.2012.24B056.

(5) Lochab, B.; Shukla, S.; Varma, I. K. Naturally Occurring Phenolic Sources: Monomers and Polymers. RSC Adv. 2014, 4 (42), 21712-21752. https://doi.org/10.1039/C4RA00181H.

(6) Gandini, A. Furans as Offspring of Sugars and Polysaccharides and Progenitors of a Family of Remarkable Polymers: A Review of Recent Progress. Polym. Chem. 2010, 1 (3), 245-251. https://doi.org/10.1039/B9PY00233B.

(7) Gandini, A. Furans in Polymer Chemistry. Progress in Polymer Science 1997, 22 (6), 1203-1379. https://doi.org/10.1016/S0079-6700(97)00004-X.

(8) Corbet, J.-P.; Mignani, G. Selected Patented Cross-Coupling Reaction Technologies. Chemical Reviews 2006, 106 (7), 2651-2710. https://doi.org/10.1021/cr0505268.

(9) Sun, C.-L.; Shi, Z.-J. Transition-Metal-Free Coupling Reactions. Chemical Reviews 2014, 114 (18), 9219-9280. https://doi.org/10.1021/cr400274j.

(10) Abdel Bar, F. M.; Khanfar, M. A.; Elnagar, A. Y.; Badria, F. A.; Zaghloul, A. M.; Ahmad, K. F.; Sylvester, P. W.; El Sayed, K. A. Design and Pharmacophore Modeling of Biaryl Methyl Eugenol Analogs as Breast Cancer Invasion Inhibitors. Bioorganic \& Medicinal Chemistry 2010, 18 (2), 496-507. https://doi.org/10.1016/j.bmc.2009.12.019.

(11) Al-Muaikel, N. S. Friedel-Crafts Polyketones: Synthesis, Characterization and Antimicrobial Properties of Unsaturated Polyketones and Copolyketones Based on Difurfurylidene Cycloheptanone. International Journal of Polymer Science 2011, 2011, 1-8. https://doi.org/10.1155/2011/810628.

(12) Antoniotti, S.; Santhanam, L.; Ahuja, D.; Hogg, M. G.; Dordick, J. S. Structural Diversity of Peroxidase-Catalyzed Oxidation Products of $o$-Methoxyphenols. Organic Letters 2004, 6 (12), 1975-1978. https://doi.org/10.1021/ol049448l.

(13) Li, H.; Xu, Z.; Yan, P.; Zhang, Z. C. A Catalytic Aldol Condensation System Enables One Pot Conversion of Biomass Saccharides to Biofuel Intermediates. Green Chemistry 2017, 19 (7), 1751-1756. https://doi.org/10.1039/C7GC00362E.

(14) Huang, X.; De Hoop, C. F.; Xie, J.; Wu, Q.; Boldor, D.; Qi, J. High Bio-Content Polyurethane (PU) Foam Made from Bio-Polyol and Cellulose Nanocrystals (CNCs) via Microwave Liquefaction. Materials \& Design 2018, 138, 11-20. https://doi.org/10.1016/j.matdes.2017.10.058.

(15) Ng, F.; Couture, G.; Philippe, C.; Boutevin, B.; Caillol, S. Bio-Based Aromatic Epoxy Monomers for Thermoset Materials. Molecules 2017, 22 (1), 149. https://doi.org/10.3390/molecules22010149.

(16) Kotzebue, L. R. V.; de Oliveira, J. R.; da Silva, J. B.; Mazzetto, S. E.; Ishida, H.; Lomonaco, D. Development of Fully Biobased High-Performance Bis-Benzoxazine under Environmentally Friendly Conditions. ACS Sustainable Chemistry \& Engineering 2018, 6 (4), 5485-5494. https://doi.org/10.1021/acssuschemeng.8b00340.

(17) Salum, M. L.; Iguchi, D.; Arza, C. R.; Han, L.; Ishida, H.; Froimowicz, P. Making Benzoxazines Greener: Design, Synthesis, and Polymerization of a Bio-Based Benzoxazine Fulfilling Two Principles of Green Chemistry. 53. 
(18) Sini, N. K.; Bijwe, J.; Varma, I. K. Renewable Benzoxazine Monomer from Vanillin: Synthesis, Characterization, and Studies on Curing Behavior. Journal of Polymer Science Part A: Polymer Chemistry 2014, 52 (1), 7-11. https://doi.org/10.1002/pola.26981.

(19) Kenawy, E.-R.; El-Shanshoury, A. E.-R. R.; Omar Shaker, N.; El-Sadek, B. M.; Khattab, A. H. B.; Ismail Badr, B. Biocidal Polymers: Synthesis, Antimicrobial Activity, and Possible Toxicity of Poly (Hydroxystyrene-Co-Methylmethacrylate) Derivatives. Journal of Applied Polymer Science 2011, 120 (5), 2734-2742. https://doi.org/10.1002/app.33046.

(20) Zhao, Y.; Yu, Y.; Zhang, Y.; Wang, X.; Yang, B.; Zhang, Y.; Zhang, Q.; Fu, C.; Wei, Y.; Tao, L. From Drug to Adhesive: A New Application of Poly(Dihydropyrimidin-2(1H)-One)s via the Biginelli Polycondensation. Polymer Chemistry 2015, 6 (27), 4940-4945. https://doi.org/10.1039/C5PY00684H.

(21) Thirukumaran, P.; Sathiyamoorthi, R.; Shakila Parveen, A.; Sarojadevi, M. New Benzoxazines from Renewable Resources for Green Composite Applications. Polymer Composites 2016, 37 (2), 573-582. https://doi.org/10.1002/pc.23214.

(22) Ladmiral, V.; Jeannin, R.; Fernandes Lizarazu, K.; Lai-Kee-Him, J.; Bron, P.; Lacroix-Desmazes, P.; Caillol, S. Aromatic Biobased Polymer Latex from Cardanol. European Polymer Journal 2017, 93, 785-794. https://doi.org/10.1016/j.eurpolymj.2017.04.003.

(23) Brunel, J. M. BINOL: A Versatile Chiral Reagent. Chemical Reviews 2005, 105 (3), 857-898. https://doi.org/10.1021/cr040079g.

(24) Tiemann, F. Ueber eine charakteristische Reaction des Vanillins. Berichte der deutschen chemischen Gesellschaft 1885, 18 (2), 3493-3496. https://doi.org/10.1002/cber.188501802336.

(25) Yamamoto, H.; Hoshino, T.; Uchiyama, T. Convenient Preparation and Quantification of 5,5'Diferulic Acid. Bioscience, Biotechnology, and Biochemistry 1999, 63 (2), 390-394. https://doi.org/10.1271/bbb.63.390.

(26) Vegetationsversuche unter Abschluss des Lichts. Journal for Praktische Chemie 1864, 93 (1), 15. https://doi.org/10.1002/prac.18640930101.

(27) Kelly, D. R.; Baker, S. C.; King, D. S.; de Silva, D. S.; Lord, G.; Taylor, J. P. Studies of Nitrile Oxide Cycloadditions, and the Phenolic Oxidative Coupling of Vanillin Aldoxime by Geobacillus Sp. DDS012 from Italian Rye Grass Silage. Organic \& Biomolecular Chemistry 2008, 6 (4), 787. https://doi.org/10.1039/b716915a.

(28) Delomenède, M.; Bedos-Belval, F.; Duran, H.; Vindis, C.; Baltas, M.; Nègre-Salvayre, A. Development of Novel Antiatherogenic Biaryls: Design, Synthesis, and Reactivity. Journal of Medicinal Chemistry 2008, 51 (11), 3171-3181. https://doi.org/10.1021/jm7014793.

(29) Gang, H.; Lee, D.; Choi, K.-Y.; Kim, H.-N.; Ryu, H.; Lee, D.-S.; Kim, B.-G. Development of High Performance Polyurethane Elastomers Using Vanillin-Based Green Polyol Chain Extender Originating from Lignocellulosic Biomass. ACS Sustainable Chemistry \& Engineering 2017, 5 (6), 4582-4588. https://doi.org/10.1021/acssuschemeng.6b02960.

(30) Wright, M. E.; Harvey, B. G. Polymeric Materials Made from Vanillin. 2016, US9353219B1.

(31) Wright, M. E.; Harvey, B. G. Polymeric Materials Made from Vanillin. 2017, US9815775B1.

(32) Suzuki, A. Recent Advances in the Cross-Coupling Reactions of Organoboron Derivatives with Organic Electrophiles, 1995-1998. Journal of Organometallic Chemistry 1999, 576 (1-2), 147168. https://doi.org/10.1016/S0022-328X(98)01055-9.

(33) Tawade, B. V.; Shaligram, S. V.; Valsange, N. G.; Kharul, U. K.; Wadgaonkar, P. P. Synthesis and Properties of Poly(Arylene Ether)s Based on 3-Pentadecyl 4,4'-Biphenol: Poly(Arylene Ether)s with 3-Pentadecyl 4,4'-Biphenol. Polymer International 2016, 65 (5), 567-576. https://doi.org/10.1002/pi.5095.

(34) Schmidt, B.; Riemer, M. Suzuki-Miyaura Coupling of Halophenols and Phenol Boronic Acids: Systematic Investigation of Positional Isomer Effects and Conclusions for the Synthesis of Phytoalexins from Pyrinae. The Journal of Organic Chemistry 2014, 79 (9), 4104-4118. https://doi.org/10.1021/j0500675a. 
(35) Sharma, A.; Sharma, N.; Kumar, R.; Shard, A.; Sinha, A. K. Direct Olefination of Benzaldehydes into Hydroxy Functionalized Oligo ( $p$-Phenylenevinylene)s via Pd-Catalyzed Heterodomino Knoevenagel-Decarboxylation-Heck Sequence and Its Application for Fluoride Sensing $\pi$ Conjugated Units. Chemical Communications 2010, 46 (19), 3283. https://doi.org/10.1039/c001980a.

(36) Amarasekara, A. S.; Wiredu, B.; Razzaq, A. Vanillin Based Polymers: I. An Electrochemical Route to Polyvanillin. Green Chemistry 2012, 14 (9), 2395. https://doi.org/10.1039/c2gc35645g.

(37) Nishimura, R. T.; Giammanco, C. H.; Vosburg, D. A. Green, Enzymatic Syntheses of Divanillin and Diapocynin for the Organic, Biochemistry, or Advanced General Chemistry Laboratory. Journal of Chemical Education 2010, 87 (5), 526-527. https://doi.org/10.1021/ed8001607.

(38) Grelier, S.; Cramail, H.; Llevot, A.; Carlotti, S.; Grau, E. New Process for Preparing Biphenyl Compounds. 2016, WO2016/050988A1.

(39) Llevot, A.; Grau, E.; Carlotti, S.; Grelier, S.; Cramail, H. Selective Laccase-Catalyzed Dimerization of Phenolic Compounds Derived from Lignin: Towards Original Symmetrical BioBased (Bis) Aromatic Monomers. Journal of Molecular Catalysis B: Enzymatic 2016, 125, 3441.

(40) Grelier, S.; Cramail, H.; Llevot, A.; Carlotti, S.; Grau, E. New Phenolic Polymers and Preparation Processes Thereof. 2016, WO2016/050989A1.

(41) Savonnet, E.; Grau, E.; Grelier, S.; Defoort, B.; Cramail, H. Divanillin-Based Epoxy Precursors as DGEBA Substitutes for Biobased Epoxy Thermosets. ACS Sustainable Chemistry \& Engineering 2018, 6 (8), 11008-11017. https://doi.org/10.1021/acssuschemeng.8b02419.

(42) Harvey, B. G.; Guenthner, A. J.; Lai, W. W.; Meylemans, H. A.; Davis, M. C.; Cambrea, L. R.; Reams, J. T.; Lamison, K. R. Effects of $o$-Methoxy Groups on the Properties and Thermal Stability of Renewable High-Temperature Cyanate Ester Resins. Macromolecules 2015, 48 (10), 3173-3179. https://doi.org/10.1021/acs.macromol.5b00496.

(43) Gatfield, I.-L.; Reiss, I.; Krammer, G.; Clerc, A.; Kindel, G. Use of Divanillin as a Flavouring Agent. 2006, US2006/0286237A1.

(44) Gaur, M.; Lohani, J.; Balakrishnan, V. R.; Raghunathan, P.; Eswaran, S. V. Dehydrodivanillin: Multi-Dimensional NMR Spectral Studies, Surface Morphology and Electrical Characteristics of Thin Films. Bulletin of the Korean Chemical Society 2009, 30 (12), 2895-2898. https://doi.org/10.5012/bkcs.2009.30.12.2895.

(45) Yadav, G. D.; Kirthivasan, N. Synthesis of Bisphenol-A: Comparison of Efficacy of Ion Exchange Resin Catalysts Vis-à-Vis Heteropolyacid Supported on Clay and Kinetic Modelling. Applied Catalysis A: General 1997, 154 (1-2), 29-53. https://doi.org/10.1016/S0926-860X(96)00364-X.

(46) Rubin, B. S. Bisphenol A: An Endocrine Disruptor with Widespread Exposure and Multiple Effects. The Journal of Steroid Biochemistry and Molecular Biology 2011, 127 (1-2), 27-34. https://doi.org/10.1016/j.jsbmb.2011.05.002.

(47) Ferguson, L. N. Orientation of Substitution in the Benzene Nucleus. Chemical Reviews 1952, 50 (1), 47-67. https://doi.org/10.1021/cr60155a002.

(48) Chiu, Y.-C.; Chou, I.-C.; Tseng, W.-C.; Ma, C.-C. M. Preparation and Thermal Properties of Diglycidylether Sulfone Epoxy. Polymer Degradation and Stability 2008, 93 (3), 668-676. https://doi.org/10.1016/j.polymdegradstab.2007.12.014.

(49) Cupples, A. L.; Lee, H.; Stoffey, D. G. The Design and Synthesis of Epoxy Resins for Rapid Room Temperature Cures with Primary Amines in Small Masses. In Epoxy Resins; Lee, H., Ed.; AMERICAN CHEMICAL SOCIETY: WASHINGTON, D. C., 1970; Vol. 92, pp 173-207. https://doi.org/10.1021/ba-1970-0092.ch015.

(50) Maiorana, A.; Spinella, S.; Gross, R. A. Bio-Based Alternative to the Diglycidyl Ether of Bisphenol A with Controlled Materials Properties. Biomacromolecules 2015, 16 (3), 10211031. https://doi.org/10.1021/acs.biomac.5b00014.

(51) More, A. S.; Pasale, S. K.; Honkhambe, P. N.; Wadgaonkar, P. P. Synthesis and Characterization of Organo-Soluble Poly(Ether Ether Ketone)s and Poly(Ether Ether Ketone Ketone)s Containing 
Pendant Pentadecyl Chains: Characterization of Organo-Soluble Peek S and Peekk S. Journal of Applied Polymer Science 2011, 121 (6), 3689-3695. https://doi.org/10.1002/app.34181.

(52) More, A. S.; Wadgaonkar, P. P. Bisphenol Compound and Process for Preparation Thereof. 2007, US2007/0073090A1.

(53) Kuhire, S. S.; Nagane, S. S.; Wadgaonkar, P. P. Pendant Furyl Containing Bisphenols, Polymers Therefrom and a Process for the Preparation Thereof. 2015, WO2015/140818A1.

(54) Liu, Z.; Zhang, G.; Sun, H.; Jiang, H.; Zhao, C.; Xu, D.; Li, H.; Sun, X.; Na, H. Preparation, Characterization and Thermal Properties of Tetramethylbisphenol F Epoxy Resin and Mixed Systems. Polymer International 2012, 61 (4), 565-570. https://doi.org/10.1002/pi.3205.

(55) Chen, Q.; Gao, K.; Peng, C.; Xie, H.; Zhao, Z. K.; Bao, M. Preparation of Lignin/Glycerol-Based Bis(Cyclic Carbonate) for the Synthesis of Polyurethanes. Green Chemistry 2015, 17 (9), $4546-$ 4551. https://doi.org/10.1039/C5GC01340B.

(56) Meylemans, H. A.; Groshens, T. J.; Harvey, B. G. Synthesis of Renewable Bisphenols from Creosol. ChemSusChem 2012, 5 (1), 206-210. https://doi.org/10.1002/cssc.201100402.

(57) Meylemans, H. A.; Harvey, B. G.; Reams, J. T.; Guenthner, A. J.; Cambrea, L. R.; Groshens, T. J.; Baldwin, L. C.; Garrison, M. D.; Mabry, J. M. Synthesis, Characterization, and Cure Chemistry of Renewable Bis(Cyanate) Esters Derived from 2-Methoxy-4-Methylphenol. Biomacromolecules 2013, 14 (3), 771-780. https://doi.org/10.1021/bm3018438.

(58) Harvey, B. G.; Meylemans, H. A.; Wright, M. E.; Chafin, A. Renewable Bisphenols and Resins from Salicylic Acid. 2016, US9517987B1.

(59) Zhao, S.; Huang, X.; Whelton, A. J.; Abu-Omar, M. M. Renewable Epoxy Thermosets from Fully Lignin-Derived Triphenols. ACS Sustainable Chemistry \& Engineering 2018, 6 (6), 7600-7608. https://doi.org/10.1021/acssuschemeng.8b00443.

(60) Zhao, S.; Huang, X.; Whelton, A. J.; Abu-Omar, M. M. Formaldehyde-Free Method for Incorporating Lignin into Epoxy Thermosets. ACS Sustainable Chemistry \& Engineering 2018, 6 (8), 10628-10636. https://doi.org/10.1021/acssuschemeng.8b01962.

(61) Harvey, B. G.; Guenthner, A. J.; Koontz, T. A.; Storch, P. J.; Reams, J. T.; Groshens, T. J. Sustainable Hydrophobic Thermosetting Resins and Polycarbonates from Turpentine. Green Chemistry 2016, 18 (8), 2416-2423. https://doi.org/10.1039/C5GC02893K.

(62) Hernandez, E. D.; Bassett, A. W.; Sadler, J. M.; La Scala, J. J.; Stanzione, J. F. Synthesis and Characterization of Bio-Based Epoxy Resins Derived from Vanillyl Alcohol. ACS Sustainable $\begin{array}{lllll}\text { Chemistry \& Engineering 2016, } 4 \text { (8), 4328-4339. } & \text { 4 }\end{array}$ https://doi.org/10.1021/acssuschemeng.6b00835.

(63) Nicastro, K. H.; Kloxin, C. J.; Epps, T. H. Potential Lignin-Derived Alternatives to Bisphenol A in Diamine-Hardened Epoxy Resins. ACS Sustainable Chemistry \& Engineering 2018, 6 (11), 14812-14819. https://doi.org/10.1021/acssuschemeng.8b03340.

(64) Avadhani, C. V.; Wadgaonkar, P. P.; Swaminathan, S. 1,1-Bis(4-Hydroxyphenyl)-3Alkylcyclohexanes, Method for Their Preparation and Polycarbonates Prepared Therefrom. 2001, US6255439B1.

(65) Cho, J.-K.; Kim, S.-Y.; Lee, D.-H.; Kim, B.; Kim, B.-J.; Jung, J.-W.; Lee, J.-S. Furan-Based Curable Compound Derived from Biomass, Solvent-Free Curable Composition, and Method for Preparing Same. 2011, WO2011/030991A1.

(66) Urban, C.; Schäffeler, N. Furan-Based Amines as Curing Agents for Epoxy Resins in Low VOC Applications. 2015, WO2015/124792A1.

(67) Pion, F.; Reano, A. F.; Ducrot, P.-H.; Allais, F. Chemo-Enzymatic Preparation of New Bio-Based Bis- and Trisphenols: New Versatile Building Blocks for Polymer Chemistry. RSC Advances 2013, 3 (23), 8988. https://doi.org/10.1039/c3ra41247d.

(68) Reano, A. F.; Chérubin, J.; Peru, A. M. M.; Wang, Q.; Clément, T.; Domenek, S.; Allais, F. Structure-Activity Relationships and Structural Design Optimization of a Series of $p$ Hydroxycinnamic Acids-Based Bis- and Trisphenols as Novel Sustainable Antiradical/Antioxidant Additives. ACS Sustainable Chemistry \& Engineering 2015, 3 (12), 3486-3496. https://doi.org/10.1021/acssuschemeng.5b01281. 
(69) Niemetz, R.; Gross, G. G. Enzymology of Gallotannin and Ellagitannin Biosynthesis. Phytochemistry 2005, 66, 2001-2011.

(70) Duan, X.-F.; Feng, J.-X.; Zi, G.-F.; Zhang, Z.-B. A Convenient Synthesis of Unsymmetrical Pinacols by Coupling of Structurally Similar Aromatic Aldehydes Mediated by Low-Valent Titanium. Synthesis 2009, 2009 (02), 277-282. https://doi.org/10.1055/s-0028-1083264.

(71) Li, J.-T.; Bian, Y.-J.; Zang, H.-J.; Li, T. PINACOL COUPLING OF AROMATIC ALDEHYDES AND KETONES USING MAGNESIUM IN AQUEOUS AMMONIUM CHLORIDE UNDER ULTRASOUND. Synthetic Communications 2002, 32 (4), 547-551. https://doi.org/10.1081/SCC-120002400.

(72) McMurry, J. E.; Melton, J. Mild Procedure for Transforming Nitro Groups into Carbonyls. Application to the Synthesis of Cis-Jasmone. Journal of the American Chemical Society 1971, 93 (20), 5309-5311. https://doi.org/10.1021/ja00749a086.

(73) Mukaiyama, T.; Sato, T.; Hanna, J. Reductive Coupling of Carbonyl Compounds to Pinacols and Olefins by Using TiCl4 and Zn. Chemistry Letters 1973, 1041-1044.

(74) Harvey, B. G.; Guenthner, A. J.; Meylemans, H. A.; Haines, S. R. L.; Lamison, K. R.; Groshens, T. J.; Cambrea, L. R.; Davis, M. C.; Lai, W. W. Renewable Thermosetting Resins and Thermoplastics from Vanillin. Green Chemistry 2015, 17 (2), 1249-1258. https://doi.org/10.1039/C4GC01825G.

(75) Griehl, W.; Lückert, H. Hardenable Resin Mixtures. 1962, US3061588.

(76) Pearl, I. A. Reactions of Vanillin and Its Derived Compounds. XVI. ${ }^{1}$ The Synthesis of Vanillil ${ }^{2}$. Journal of the American Chemical Society 1952, 74 (17), 4260-4262. https://doi.org/10.1021/ja01137a005.

(77) Amarasekara, A. S.; Hasan, M. A. Vanillin Based Polymers: III. Electrochemical Dimerization of Vanillin Revisited and Synthesis of Hydrovanilloin-Formaldehyde Polymer. Polymer Science Series B 2016, 58 (3), 307-312. https://doi.org/10.1134/S1560090416030015.

(78) Rumpel, W. Verfahren Zur Herstellung von Divanillyden-Cyclohexanon. AT180258 1954.

(79) Sardjiman, S.; Reksohadiprodjo, M.; Hakim, L.; Van Der Goot, H.; Timmerman, H. 1,5-Diphenyl1,4-Pentadiene-3-Ones and Cyclic Analogues as Antioxidative Agents. Synthesis Ans StructureActivity Relationship. Eur. J. Med. Chem. 1997, 32, 625-630.

(80) Rao, V. S.; Samui, A. B. Molecular Engineering of Photoactive Liquid Crystalline Polyester Epoxies Containing Benzylidene Moiety. Journal of Polymer Science Part A: Polymer Chemistry 2008, 46 (23), 7637-7655. https://doi.org/10.1002/pola.23064.

(81) Shibata, M.; Ohkita, T. Fully Biobased Epoxy Resin Systems Composed of a Vanillin-Derived Epoxy Resin and Renewable Phenolic Hardeners. European Polymer Journal 2017, 92, 165173. https://doi.org/10.1016/j.eurpolymj.2017.05.007.

(82) Salon, M. C.; Gandini, A.; Cheradame, H. The Anionic Polymerisation of Furfurylidene Acetone: Evidence for Isomerisation Preceding Propagation. Polymer Bulletin 1984, 12 (5). https://doi.org/10.1007/BF00255432.

(83) Viallet, A.; Gandini, A. Synthesis and Photodimerization of 2,5-Furandiacrylic Acid. Journal of Photochemistry and Photobiology, A: Chemistry 1990, 54, 129-130.

(84) Wang, J.-X.; Kang, L.; Hu, Y.; guo Wei, B. SYNTHESIS OF BIS (SUBSTITUTED BENZYLIDENE)CYCLOALKANONE USING SUPPORTED REAGENTS AND MICROWAVE IRRADIATION. Synthetic Communications 2002, 32 (11), 1691-1696. https://doi.org/10.1081/SCC-120004261.

(85) West, R. M.; Liu, Z. Y.; Peter, M.; Gärtner, C. A.; Dumesic, J. A. Carbon-Carbon Bond Formation for Biomass-Derived Furfurals and Ketones by Aldol Condensation in a Biphasic System. Journal of Molecular Catalysis A: Chemical 2008, 296 (1-2), 18-27. https://doi.org/10.1016/j.molcata.2008.09.001.

(86) West, R. M.; Liu, Z. Y.; Peter, M.; Dumesic, J. A. Liquid Alkanes with Targeted Molecular Weights from Biomass-Derived Carbohydrates. ChemSusChem 2008, 1 (5), 417-424. https://doi.org/10.1002/cssc.200800001. 
(87) Bessonov, I. V.; Kopitsyna, M. N.; Polezhaev, A. V.; Nelyub, V. A. A Mechanistic Study of the Reaction between Furfural-Acetone Resins and Polyamines. Polymer Science Series D 2016, 9 (1), 17-21. https://doi.org/10.1134/S1995421216010044.

(88) Harvey, B. G.; Sahagun, C. M.; Guenthner, A. J.; Groshens, T. J.; Cambrea, L. R.; Reams, J. T.; Mabry, J. M. A High-Performance Renewable Thermosetting Resin Derived from Eugenol. ChemSusChem 2014, 7 (7), 1964-1969. https://doi.org/10.1002/cssc.201400019.

(89) Harvey, B. G. Renewable Resins and Thermoplastics from Eugenol. 2017, US9751991B1.

(90) Mliki, K.; Trabelsi, M. Chemicals from Biomass: Efficient and Facile Synthesis of 5,5'(OxyBis(Methylene))Bis-2-Furfural from 5-Hydroxymethylfurfural. Industrial Crops and Products 2015, 78, 91-94. https://doi.org/10.1016/j.indcrop.2015.10.026.

(91) Casanova, O.; Iborra, S.; Corma, A. Chemicals from Biomass: Etherification of 5Hydroxymethyl-2-Furfural (HMF) into 5,5'(Oxy-Bis(Methylene))Bis-2-Furfural (OBMF) with Solid Catalysts. Journal of Catalysis 2010, $275 \quad$ (2), 236-242. https://doi.org/10.1016/j.jcat.2010.08.002.

(92) Shinde, S.; Rode, C. Selective Self-Etherification of 5-(Hydroxymethyl)Furfural over Sn-Mont Catalyst. Catalysis Communications 2017, 88, 77-80. https://doi.org/10.1016/j.catcom.2016.09.034.

(93) Dunlop, A. P. Bis(Hydroxymethylfurfuryl)-Butylamine and Method of Preparation. 1980, US4219485.

(94) Dunlop, A. P. N,N-Bis(5-Hydroxymethylfurfuryl)-Methylamine and Process of Preparation. 1980, US4219486.

(95) Xu, Z.; Yan, P.; Liu, K.; Wan, L.; Xu, W.; Li, H.; Liu, X.; Zhang, Z. C. Synthesis of Bis(Hydroxylmethylfurfuryl)Amine Monomers from 5-Hydroxymethylfurfural. ChemSusChem 2016, 9 (11), 1255-1258. https://doi.org/10.1002/cssc.201600122.

(96) Amarasekara, A. S.; Razzaq, A. Vanillin-Based Polymers-Part II: Synthesis of Schiff Base Polymers of Divanillin and Their Chelation with Metal Ions. ISRN Polymer Science 2012, 2012, 1-5. https://doi.org/10.5402/2012/532171.

(97) Wan, J.; Gan, B.; Li, C.; Molina-Aldareguia, J.; Kalali, E. N.; Wang, X.; Wang, D.-Y. A Sustainable, Eugenol-Derived Epoxy Resin with High Biobased Content, Modulus, Hardness and Low Flammability: Synthesis, Curing Kinetics and Structure-Property Relationship. Chemical Engineering Journal 2016, 284, 1080-1093. https://doi.org/10.1016/j.cej.2015.09.031.

(98) Zou, Q.; Ba, L.; Tan, X.; Tu, M.; Cheng, J.; Zhang, J. Tunable Shape Memory Properties of RigidFlexible Epoxy Networks. Journal of Materials Science 2016, 51 (23), 10596-10607. https://doi.org/10.1007/s10853-016-0281-1.

(99) Faye, I.; Decostanzi, M.; Ecochard, Y.; Caillol, S. Eugenol Bio-Based Epoxy Thermosets: From Cloves to Applied Materials. Green Chem. 2017, 19 (21), 5236-5242. https://doi.org/10.1039/C7GC02322G.

(100) Wan, J.; Gan, B.; Li, C.; Molina-Aldareguia, J.; Li, Z.; Wang, X.; Wang, D.-Y. A Novel Biobased Epoxy Resin with High Mechanical Stiffness and Low Flammability: Synthesis, Characterization and Properties. Journal of Materials Chemistry A 2015, 3 (43), 21907-21921. https://doi.org/10.1039/C5TA02939B.

(101) Wan, J.; Zhao, J.; Gan, B.; Li, C.; Molina-Aldareguia, J.; Zhao, Y.; Pan, Y.-T.; Wang, D.-Y. Ultrastiff Biobased Epoxy Resin with High $T_{\mathrm{g}}$ and Low Permittivity: From Synthesis to Properties. ACS Sustainable Chemistry \& Engineering 2016, 4 (5), 2869-2880. https://doi.org/10.1021/acssuschemeng.6b00479.

(102) Balamurugan, R.; Kannan, P. 1,3,4-Oxadiazole Epoxy Resin-Based Liquid Crystalline Thermosets and Their Cure Kinetics. Journal of Materials Science 2010, 45 (5), 1321-1327. https://doi.org/10.1007/s10853-009-4085-4.

(103) Livant, P.; Webb, T. R.; Xu, W. Reaction of Resorcinol With Acetone. The Journal of Organic Chemistry 1997, 62 (3), 737-742. https://doi.org/10.1021/jo961647y. 
(104) Cheng, J.; Chen, J.; Yang, W. T. Synthesis and Characterization of Novel Multifunctional Epoxy Resin. Chinese Chemical Letters 2007, 18 (4), 469-472. https://doi.org/10.1016/j.cclet.2006.12.033.

(105) Wang, R.; Liu, Z.-Q. Ugi Multicomponent Reaction Product: The Inhibitive Effect on DNA Oxidation Depends upon the Isocyanide Moiety. The Journal of Organic Chemistry 2013, 78 (17), 8696-8704. https://doi.org/10.1021/jo401426n.

(106) Brzozowski, A. M.; Pike, A. C. W.; Dauter, Z.; Hubbard, R. E.; Bonn, T.; Engström, O.; Öhman, L.; Greene, G. L.; Gustafsson, J.-Å.; Carlquist, M. Molecular Basis of Agonism and Antagonism in the Oestrogen Receptor. Nature 1997, 389 (6652), 753-758. https://doi.org/10.1038/39645.

(107) Hu, J.; Zhang, Q.; Lee, D.-J. Kraft Lignin Biorefinery: A Perspective. Bioresource Technology 2018, 247, 1181-1183. https://doi.org/10.1016/j.biortech.2017.08.169.

(108) Dessbesell, L.; Yuan, Z.; Hamilton, S.; Leitch, M.; Pulkki, R.; Xu, C. C. Bio-Based Polymers Production in a Kraft Lignin Biorefinery: Techno-Economic Assessment: Bio-Based Polymer Production in a Kraft Lignin Biorefinery. Biofuels, Bioproducts and Biorefining 2018, 12 (2), 239-250. https://doi.org/10.1002/bbb.1834. 